\title{
Relações de Identidade em Modelos Paralelistas: Morfologia E Fonologia
}

(Identity Relations in Paralelistic Models: Morphology and Phonology)

\author{
Carlos Alexandre Gonçalves \\ (Universidade Federal do Rio de Janeiro)
}

\begin{abstract}
This paper discusses aspects of brazilian portuguese morphology-phonology interface within the framework of optimality theory. The paper rewiews the notion of faithfulness in three parellel models: (a) classic optimality (Prince E Smolensky, 1993), (b) correspondence (McCarthy E Prince, 1995; Benua, 1995) and (c) sympathy (McCarthy, 1998). While McCarthy's (1998) sympathy theory is a response to explaining phonological opacity within parallel optimality theory, it is demonstrated that non-concatenative morphology process, like truncation and lexical blend, also can be described with this framework.
\end{abstract}

KEY-WORDS: optimality theory; non-concatenative morphology; truncation; opacity; sympathy theory.

RESUMO: Neste artigo, confronto três abordagens paralelistas sobre o papel das restrições de fidelidade na gramática universal: (a) a otimalidade clássica (Prince E Smolensky, 1993), (b) a teoria da correspondência (McCarthy E Prince, 1995) e (c) a simpatia (McCarthy E Prince, 1998). Ilustrando cada modelo com dados do português, procuro mostrar que as divergências decorrem do nivel de representação utilizado como parâmetro. Argumento que a simpatia, originalmente proposta por McCarthy (1998) para dar conta de processos fonológicos opacos, pode ser estendida para a análise de processos morfológicos não-concatenativos, como o truncamento e o blend lexical.

PALAVRAS-CHAVE: teoria da otimalidade; morfologia não-concatenativa; truncamento; opacidade; simpatia. 


\section{Introdução}

Neste texto, confronto três abordagens paralelistas sobre o papel das restrições de fidelidade na Gramática Universal: (a) a Otimalidade Clássica (Prince \& Smolensky, 1993), (b) a Teoria da Correspondência (McCarthy \& Prince, 1995; Benua, 1995) e (c) a Simpatia (McCarthy \& Prince, 1998). Ilustrando cada modelo com dados do português, procuro mostrar que as divergências decorrem do nível de representação utilizado como parâmetro. Na Otimalidade Clássica, a identidade se restringe à checagem do grau de semelhança entre a forma lexical de base (o input) e os vários candidatos a output gerados por GER. Na Correspondência, ao contrário, restrições de fidelidade atuam em vários domínios que envolvem identidade entre representações lingüísticas (input/output; base/reduplicante; e base/ truncamento, entre outros), o que permite avaliar a similitude não só de inputs e outputs, mas também de derivantes e derivados de processos morfológicos produtivos (Benua, 1995). Na Simpatia, um candidato mal-sucedido funciona como modelo para a seleção da forma final, levando as restrições de fidelidade a focalizar o grau de (des)semelhança entre ele e os demais concorrentes.

Extremamente importantes para a Teoria Gerativa (Fukazawa, 1997), relações de identidade minimizam a aplicação livre de regras, de modo a prevenir apagamentos, inserções e mudanças sem qualquer tipo de motivação. Embora desejável, a preservação da identidade input-output é assumida, mas não explicitada em outros modelos formais. A Otimalidade (doravante OT) se mostra inovadora, nas palavras de Costa (2000, p. 34), porque "formaliza e integra nos instrumentos básicos da teoria, nomeadamente no conjunto de restriçôes violáveis e universais, uma noção que era apenas implicitamente assumida noutros quadros teóricos". Restrições de fidelidade militam contra discrepâncias entre representações subjacente e de superfície, fazendo com que eventuais disparidades input-output sejam devidamente explicadas.

Apesar de divergentes em vários aspectos, as abordagens aqui apresentadas seguem os princípios arquiteturais estabelecidos em Prince \& Smolensky (1993), sendo, por isso, igualmente otimalistas e parelelistas: a melhor satisfação à hierarquia é determinada com referência a todas as restrições e a todos os candidatos a output, sem derivação serial. Em decorrência do parelelismo, não se estabelecem níveis intermediários de representação, uma vez que AVAL opera num só estrato, selecionando o candidato mais harmônico a partir de uma única escala hierárquica de restrições. 
O texto se estrutura da seguinte maneira: na seção 1, descrevo as restrições de identidade input-output, focalizando o conflito entre MARCAÇÃ̃O e FIDELIDADE. O fenômeno da epêntese vocálica ('pakinto', 'akine'), analisado por Collischonn (2000), será utilizado para ilustrar a abordagem otimalista clássica. Na seção seguinte, listo as diferenças entre OT Clássica e Teoria da Correspondência, comentando os argumentos apresentados por McCarthy \& Prince (1995) e Benua (1995) para estender as relações de identidade a outros níveis de representação lingüística. Processos morfológicos não-concatenativos, como a Hipocorização ('Xande', por 'Alexandre') e o Truncamento ('salafra', por 'salafrário'), serão usados para exemplificar o modelo. Na seção 3, mostro a relevância da Simpatia no paradigma da OT, evidenciando que é possível tratar a questão da opacidade fonológica sem utilizar ciclos derivacionais, como faz Kiparsky (1997). O confronto entre Simpatia e Correspondência também é feito na seção 3 , na qual rediscuto os resultados da Hipocorização, obtidos, na seção 2, via Correspondência. Na seção seguinte (4), aparecem as principais conclusões do trabalho e uma reflexão geral sobre fidelidade em fenômenos morfológicos (não-concatenativos e aglutinativos).

Em decorrência de seu status embrionário, o trabalho prático feito em Simpatia e Correspondência ainda é relativamente escasso, sobretudo para o português. Ao apresentar e exemplificar cada um desses modelos, procuro também discutir os aspectos teórico-metodológicos que já vêm sendo questionados em recentes artigos editados pelo $\mathrm{ROA}^{1}$, como o de Hale, Kissock e Reiss (2001), o de Sanders (2001) e o de Walther (2002). Nesse sentido, pretendo fornecer uma visão crítica e corrente sobre o papel das relações de identidade na Gramática, a partir de abordagens que enfatizam a violabilidade, o conflito e a hierarquia de restrições universais.

\section{Restrições de Fidelidade na OT Clássica}

No paradigma da Otimalidade, formas de output tendem a ser geradas pelo conflito entre restrições de marcação e restrições de fidelidade (Kager, 1999). As primeiras regulam a boa-formação de estruturas segmentais e/ ou prosódicas, levando à escolha de outputs menos marcados. As últimas,

\footnotetext{
1 Abreviação de Rutgers Optimality Archieve - um site da Internet dedicado à catalogação de textos sobre otimalidade e ao debate de questões teóricas. O atual endereço do ROA é http:// roa.rutgers.edu, que substitui o anterior http://ruccs.rutgers.edu/roa.html.
} 
diferentemente, conspiram contra qualquer tipo de mudança, fazendo com que os outputs destoem minimamente dos inputs lexicais. Dessa forma, restrições de marcação se voltam apenas para os candidatos a output, enquanto as de fidelidade focalizam a relação entre inputs e outputs, proibindo inserções e apagamentos, por exemplo.

Sem levar em conta as formas de base, restrições de marcação são exigências estruturais como as que se seguem: (a) sílabas têm de ser abertas (NÃO-CODA) ${ }^{2}$, (b) sílabas devem ter ataques (ONSET) e (c) sílabas não podem apresentar margens complexos (*COMPLEX). As de fidelidade, ao contrário, requerem total semelhança entre input e output, determinando mapeamento de um-para-um entre essas duas linhas de representação lingüística. São imposições do tipo: (i) o output tem de preservar todos os elementos do input, (ii) o output deve preservar a ordem linear dos constituintes do input e (c) traços de segmentos do input devem aparecer nos segmentos do output.

Em Prince \& Smolensky (1993), FIDELIDADE é representada basicamente por MAX-IO (MAXimalidade Input-Output) e DEP-IO (DEPendência Input-Output). Com o objetivo de evitar disparidades entre estruturas subjacentes e representações finais, MAX-IO e DEP-IO impõem univocidade entre forma de base e candidatos a output. Sherrard (1997, p. 119) define essas restrições da seguinte maneira:

(01) MAX-IO: cada elemento do input é também elemento do output, isto é, o output deve estar maximamente contido no input.

(02) DEP-IO: cada elemento do output é também um elemento do input, isto é, o input deve estar maximamente contido no output.

Como restrições são exigências que podem ou não ser respeitadas (Prince \& Smolensky, 1993), uma transgressão de MAX levará à perda de um elemento do input (apagamento). Uma violação de DEP, ao contrário, será responsável pela adição de um segmento no output (epêntese). Quando MAX e DEP são restrições não-dominadas, o output será inteiramente fiel à especificação do input. Por outro lado, sempre que restrições estruturais estiverem ranqueadas mais alto, serão selecionados outputs menos marcados. As duas possibilidades de dominância são representadas a seguir:

2 Seguindo convenção usada em trabalhos otimalistas, represento as restrições sempre em caixa alta. 
(03) Fidelidade $>>$ Marcação

(padrões lexicalmente especificados)

Marcação $>>$ Fidelidade

(padrões menos marcados estruturalmente)

A hierarquização entre restrições estruturais e de fidelidade torna visíveis os valores não-marcados de uma língua (Costa, 2000). Tomemos como exemplos os dados de (04) a seguir, cuja grafia sugere a existência de várias obstruintes em travamento silábico (oclusivas e fricativas labiais). Como se sabe, as únicas consoantes que ocorrem na posição implosiva em português são /S/, /N/, /R/ e /l/ (Cristófaro Silva, 1998), de modo que a posição de coda não é preenchida por qualquer tipo de segmento. O próprio Mattoso Camara Jr. (1970) já havia atentado para o fato de os vocábulos de (04) serem proparoxítonos, havendo franca realização de um /i/ postônico nãofinal entre o suposto grupo consonântico.

$\begin{array}{clll}\text { (04) mogno } & \text { acne } & \text { afta } & \text { néctar } \\ \text { ritmo } & \text { pacto } & \text { impacto } & \text { invicto } \\ \text { apto } & \text { rapto } & \text { compacto } & \text { intacto }\end{array}$

Nos dados de (04), o acréscimo vocálico pode ser explicado pelo conflito entre uma restrição silábica (CODA COND) e uma restrição de fidelidade (DEP). CODA COND (CONDições sobre a CODA) impõe limites ao preenchimento da margem direita da sílaba, impedindo que determinados segmentos apareçam nessa posição. DEP, por sua vez, milita contra qualquer tipo de inserção, uma vez que a mesma não teria paralelo no input $^{3}$. Na análise de Collischonn (2000, p. 301), CODA COND bloqueia segmentos que não tenham especificação [- vocálico, + soante] ou [- soante, + contínuo, + coronal]. Por serem [- soante, - contínuo], oclusivas não estão licenciadas para coda. O mesmo acontece com /f/ ('afta'), que, apesar de ser [- soante, + contínuo], tem especificação [- coronal], o que não o autoriza a ocupar essa posição na estrutura da sílaba.

O impasse criado por CODA COND não é solucionado com a síncope das obstruintes (*'nétar', *'impato', *invito’), mas com a inserção da

\footnotetext{
3 Da mesma forma que Lee (1999) e Collischonn (2000), considero inputs as formas sem o /i/ postônico final epentético.
} 
vogal /i/ ('néquitar', 'invíquito’, ‘impáquito’). Dessa maneira, MAX (uma restrição anti-apagamento) nunca é violada, enquanto DEP (uma restrição anti-epêntese) é sistematicamente transgredida, ocupando lugar mais baixo na hierarquia. Para evitar a possibilidade de o encontro consonantal ser silabado no ataque, outra restrição estrutural entra em jogo: SONOR (SONORidade), que "impede a ocorrência de seqüências de consoantes no onset em que a diferença no grau de sonoridade é pequena" (Collischonn, 2000, p. 301) ou nula, constituindo, portanto, um platô. O Tableau abaixo ilustra a seleção do candidato ótimo para o input 'pacto"4 .

(05)

\begin{tabular}{|c|c|c|c|c|c|c|}
\hline \multicolumn{2}{|c|}{ /'pakto/ } & \multirow[t]{2}{*}{ SONOR } & \multirow[t]{2}{*}{ MAX } & \multirow{2}{*}{$\begin{array}{c}\text { CODA- } \\
\text { COND } \\
* !\end{array}$} & \multirow[t]{2}{*}{ DEP } & \multirow{2}{*}{$\begin{array}{c}\text { NÃO } \\
\text { CODA } \\
*\end{array}$} \\
\hline a. & pak.to & & & & & \\
\hline b. & pa.ki.to & & & & $*$ & \\
\hline c. & pa.to & & $* !$ & & & \\
\hline d. & pa.kto & $* !$ & & & & \\
\hline
\end{tabular}

Os candidatos ${ }^{5}$ (c) e (d) cometem uma violação fatal e são sumariamente eliminados, uma vez que SONOR e MAX, embora não hierarquizadas entre si, constituem restrições não-dominadas. Como essas restrições são as mais altas da hierarquia, outputs ótimos nunca podem cancelar segmentos ou silabar duas consoantes com mesmo grau de sonoridade (platô)

4 Tableau é o recurso expositório utilizado para demonstrar o efeito de AVAL. Nele, as restrições são dispostas, da esquerda para a direita, de acordo com a hierarquia estabelecida. No topo da coluna, aparece a forma de input, em relação à qual as diversas candidatas, relacionadas na mesma coluna, serão avaliadas, levando-se em conta o Princípio do Paralelismo (Prince \& Smolensky, 1993). O output considerado ótimo é representado por $\left(\varpi^{*}\right)$, seja por cometer menos violações $\left(^{*}\right)$, seja por não infringir restrições fatais (*!), as mais altas na hierarquia, responsáveis pela eliminação de candidatos. Linhas sólidas representam certeza quanto ao ordenamento das restrições. Linhas pontilhadas, ao contrário, indicam que as restrições que a ladeiam (ainda) não se encontram crucialmente hierarquizadas - o intercâmbio não modifica o resultado. Por fim, áreas sombreadas sinalizam violações irrelevantes para o candidato, uma vez que restrições de nível mais alto selaram seu destino, eliminando-o.

5 O Tableau (05) deve ser interpretado como resumitivo, uma vez que outras restrições são igualmente relevantes no que diz respeito à estrutura da sílaba, como PICO (sílabas devem núcleo) e ATAQUE (sílabas não podem se iniciar por vogais). Dessa forma, um candidato como 'pa.k.to' não aparece no Tableau por infringir uma restrição ainda mais alta na hierarquia: PICO. 
no onset. A dominância de MAX sobre CODA COND bloqueia a queda da oclusiva, eliminando um candidato não-marcado (com duas sílabas CV). $\mathrm{O}$ destino do candidato (a) é selado por CODA COND, que impede a presença de $/ \mathrm{k} /$ na posição de coda. Apesar de infringir DEP, (b) emerge como forma ótima, uma vez que essa restrição é ranqueada mais baixo. Uma restrição de fidelidade (DEP) é violada para satisfazer uma restrição estrutural (CODA COND). Portanto, o candidato selecionado não é inteiramente fiel ao input, mas constitui forma não-marcada na língua, uma vez que apresenta somente sílabas abertas.

Como se vê em (05), uma restrição estrutural (CODA COND) está em conflito com uma restrição de fidelidade (DEP) e ocupa posição mais alta que ela no ranking. Os efeitos dessa restrição dominada são visíveis na forma de output selecionada, dando mostras do que McCarthy \& Prince (1994) denominam de "Emergência do Não-Marcado": nas situações em que FIDELIDADE é dominada por MARCAÇÃO, as estruturas que emergem revelam padrões considerados mais básicos na língua.

Uma vez que incorpora a noção de fidelidade nos instrumentos básicos da teoria, a OT consegue expressar as divergências entre estruturas subjacentes e de superfície mais natural e satisfatoriamente que outros modelos gerativos. No exemplo em questão, a não-igualdade entre o input ('pakto') e o output ('pa.ki.to') resulta da necessidade de preservar os padrões silábicos da língua, satisfazendo, portanto, uma exigência de natureza estrutural. Essa satisfação, no entanto, tem um preço: violar uma restrição que requer total semelhança entre forma de base e forma final, tornando ótimo um candidato com um segmento sem qualquer paralelo no input.

O conflito entre restrições de fidelidade e restrições de marcação também permite explicar o desenvolvimento da linguagem pela criança. De acordo com Gnanadesikan (1995), a aquisição pode ser vista como um processo que promove identidade à fala adulta a partir de um estágio inicial em que MARCAÇÃO é dominante, como se vê em (06). Nessa fase, restrições que regulam estruturas não-marcadas são capazes de impedir que formas marcadas do output adulto sejam produzidas pela criança. MARCAÇÃO, nesse ponto, reflete, nas palavras do autor, "a habilidade rudimentar da criança para produzir contrastes sofisticados" (Gnanadesikan, 1995, p. 21). Como contrastes são necessários para suportar o léxico adulto, condições de boa-formação vão sendo progressivamente suplantadas por res- 
trições de fidelidade ao output adulto, que, como se vê no esquema abaixo, caracteriza-se por um balanceamento entre MARCAÇÃO e FIDELIDADE, ranqueadas alternadamente.

(06)

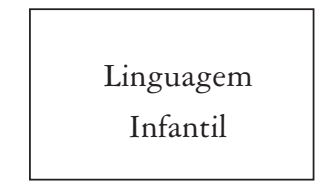

Marcação $>>$ Fidelidade

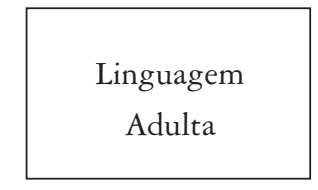

Marcação $>>$ Fidelidade $>>$ Marcação $>>$ Fidelidade

Estágios iniciais de aquisição da linguagem são caracterizados pelo ranking MARCAÇÃO >> FIDELIDADE. Em decorrência, superficializam-se formas menos complexas do ponto-de-vista prosódico, como sílabas $\mathrm{CV}$ e palavras mínimas (com um único pé dissilábico). Processos morfológicos não-aglutinativos, como a Hipocorização (Gonçalves, 2004), também se materializam pela dominância de MARCAÇÃO sobre FIDELIDADE, como apontarei mais adiante, mas há diferenças quanto ao tipo de restrição de fidelidade dominado em cada caso.

Na sua apresentação em Prince \& Smolensky (1993), a OT é aplicada basicamente à Fonologia. Quando fenômenos morfológicos começam a ser investigados no âmbito da teoria, o formato do modelo sofre modificações importantes, sobretudo no que diz respeito ao papel desempenhado pelas restrições de fidelidade. Processos não-concatenativos, sempre marginalizados nas abordagens estruturalistas e gerativistas, são analisados de modo bastante natural com os instrumentos da OT, mas levam o modelo a redefinir a relação entre os níveis de representação lingüística.

De meados da década de 90 aos dias de hoje, a OT assiste ao desenvolvimento de dois sub-modelos paralelistas que lidam com a questão da identidade intra-representacional: (a) a Correspondência e (b) a Simpatia. Em linhas gerais, os refinamentos se devem ao fato de processos morfoprosódicos, como a Infixação, serem diferentes de operações puramente fonológicas (Spencer, 1991). Se, por um lado, mecanismos morfoprosódicos requerem a presença de um input, por outro, não menos relevante é delimitação de uma base, haja vista contribuírem com algum tipo de significado. 
Operações morfológicas não processadas pela adjunção sintagmática de morfemas foram progressivamente ganhando destaque na OT, desde o trabalho pioneiro de McCarthy \& Prince (1994) sobre o fenômeno da Reduplicação. Extensões, no entanto, foram necessárias para lidar com questões dessa natureza, de modo a diferenciar mudanças morfologicamente motivadas de alterações puramente fonológicas. Em decorrência, processos de interface Morfologia-Fonologia passaram a ocupar lugar de destaque na Teoria da Correspondência - modelo que oferece instrumentos mais eficazes para o estudo da chamada Morfologia Não-Concatenativa. Em resumo, a OT Clássica não é capaz de descrever processos morfológicos satisfatoriamente, haja vista que eles requerem referência a outras entidades representacionais, além do input e do output.

\section{Restrições de Fidelidade \& Correspondência}

Operações morfológicas freqüentemente levam a modificações no conteúdo material de raízes e afixos, tendo em vista que o encadeamento pode gerar acréscimos, alterações ou apagamentos nas realizações de superfí$\mathrm{cie}^{6}$. Dessa forma, violações de FIDELIDADE são comuns no componente morfológico, uma vez que a ligação de formativos, obedecendo a restrições estruturais, preserva os padrões silábicos e acentuais da língua.

Sem conteúdo segmental subjacente, processos não-concatenativos são ainda mais especiais fonologicamente. Nesse tipo de operação, violações de FIDELIDADE não se justificam por pressões de natureza fonotática, uma vez que mudanças nas formas de base levam à expressão de um significado, sinalizando a existência de um morfema. Processos não-concatenativos promovem alterações fonológicas condicionadas morfologicamente e, dessa maneira, diferem da alomofia - uma variação formal motivada, fonologicamente, pela adjunção linear de formativos (ver nota 6).

\footnotetext{
6 Por exemplo, a realização do sufixo modal que forma adjetivos a partir de substantivos é condicionada pela existência de /1/ no onset da sílaba final: quando essa sílaba apresenta uma lateral, o sufixo se manifesta como -ar, como ocorre em 'escalar', 'escolar' e 'milenar'. Nos demais casos, a consoante do sufixo se realiza como líquida ('vital', 'mortal', 'constituicional'). Em outras palavras, a realização do sufixo é condicionada pela presença de uma lateral no final da raiz, coibindo formas com configuração *lVl, com uma lateral em onset e outra em coda. A consoante do sufixo contorna, obrigatoriamente, a da raiz, de modo a torná-la diferente da que a antecede na sílaba final do derivado. O fenômeno que aparece nesses dados é o da dissimilação e a restrição relevante é da família OCP, que advoga contra a presença de segmentos adjacentes idênticos.
} 
Como operações não-concatenativas são diferentes em forma e em função, as relações de identidade não podem atuar como nos processos puramente fonológicos ou nas realizações alomórficas: a identidade deve ser checada não entre uma única forma de input e uma de output, mas entre inputs (palavra-matriz e morfema) e outputs ou mesmo entre outputs (base e produto de processos morfológicos).

A Teoria da Correspondência, proposta por McCarthy \& Prince (1995), amplia a noção de FIDELIDADE originalmente estabelecida em Prince \& Smolensky (1993). Essa extensão é necessária simplesmente porque a Morfologia é diferente: se, por um lado, acessa informações prosódicas e se sujeita a pressões fonotáticas, por outro, manifesta um conteúdo e, por isso mesmo, formas subjacentes nunca podem ser exatamente idênticas às de superfície. Por exemplo, os derivados 'japa' e 'Maraca' diferem dos derivantes 'japonês' e 'Maracanã', nesta ordem, não porque uma restrição como NÃO-CODA seja responsável pela eliminação de sílabas finais travadas, mas porque a redução é necessária para expressar o Truncamento - processo que faz as formas encurtadas veicularem um conteúdo expressivo inexistente nas formas plenas.

Por reconhecer a existência de vários tipos de identidade na Gramática Universal, a Teoria da Correspondência (doravante TC) se mostra mais adequada para o tratamento de fatos morfológicos, firmando-se como um modelo geral de fidelidade entre representações lingüísticas. Todos os domínios que envolvem identidade são contemplados a partir da seguinte definição de correspondência, formulada por McCarthy \& Prince (1995: 262):

(07) Dadas duas camadas, $S_{1}$ e $S_{2}$, correspondência é a relação $\mathbf{R}$ dos elementos de $S_{1}$ para $S_{2}$. Elementos $\alpha \in S_{1}$ e $\beta \in S_{2}$ são considerados correspondentes um do outro sempre que $\alpha R \beta$.

Em (07), $S_{1}$ e $S_{2}$ constituem variáveis que podem ser substituídas por I (Input) e O (Output) ou por quaisquer outros domínios que forcem identidade entre formas. Assim, $\mathrm{S}_{1}$ pode ser interpretado genericamente como uma base (B) sobre a qual atuam processos como a Reduplicação, o Truncamento e a Hipocorização. Nesses casos, $\mathrm{S}_{2}$ pode ser o reduplicante (R), a palavra truncada $(\mathrm{T})$ ou o hipocorístico $(\mathrm{H})$. 
Relações de correspondência impõem um número de restritores que requerem identidade entre duas camadas. Operações gramaticais não apenas cancelam ou apagam segmentos, mas podem também (a) inverter a ordem linear (metátese), (b) alterar a especificação de um traço (sonorização, nasalização) e (c) fazer com que um elemento de uma camada esteja vinculado a mais de um elemento na outra camada. MAX e DEP, apresentadas e discutidas na seção anterior, são, portanto, insuficientes para expressar as várias situações de (não)correspondência. Vejam-se, a seguir, imposições de identidade entre duas formas, aqui representadas genericamente por $S_{1}$ e $S_{2}$, como na formulação feita em (07):

(08) IDENT-T (IDENTidade de traços): Segmentos correspondentes têm o mesmo valor para o traço T. Não pode haver permuta de traços de $S_{1}$ para $S_{2}$ : a especificação dos segmentos de $S_{2}$ deve preservar a estabelecida em $S_{1}$.

(09) LIN (LINearidade): A seqüenciação linear dos elementos de $S_{2}$ deve ser idêntica à de seus correspondentes em $\mathrm{S}_{1}$. Não pode haver inversão de segmentos de $\mathrm{S}_{1}$ para $\mathrm{S}_{2}$.

(10) ANCOR D ou E (ANCORagem à Direita ou à Esquerda): Todos os elementos da periferia direita (esquerda) de $S_{1}$ têm um correspondente exatamente na periferia direita (esquerda) de $\mathrm{S}_{2}$. $\mathrm{O}$ alinhamento dos elementos de $\mathrm{S}_{2}$ deve ser idêntico ao alinhamento efetuado em $\mathrm{S}_{1}$.

(11) INTEGR (INTEGRidade): Nenhum elemento de $S_{1}$ pode ter múltiplos correspondentes em $S_{2}$. A relação de $S_{1}$ para $S_{2}$ não pode ser de um-para-muitos.

(12) UNIFORM (UNIFORMidade): Nenhum elemento de $S_{2}$ deve apresentar múltiplos correspondentes em $S_{1}$. A relação de $S_{1}$ para $S_{2}$ não pode ser de muitos-para-um.

Ao lado de MAX e DEP, as restrições acima possibilitam descrever uma série de fenômenos lingüísticos, fonológicos e/ou morfológicos, como destacarei mais adiante, por meio dos quadros (16) e (17). IDENT-T demanda completa identidade de traços entre segmentos. Em (08), a variável $\mathrm{T}$ pode ser substituída por traços concretos, como [sonoro], [coronal] e [nasal]. LIN é uma restrição que bane metáteses, ditando obediência às relações de precedência estabelecidas em determinada camada. A condição expressa em (10), ANCOR, requer alinhamento perfeito entre margens, exigindo coincidência absoluta nas periferias de formas relacionadas. UNIFORM e INTEGR devem ser interpretadas como restrições em espelho, uma vez que a primeira milita contra a coalescência e a segunda conta o 
espalhamento, exigindo estrito mapeamento de um-para-um entre dois níveis de representação ${ }^{7}$.

Benua (1995) e Urbanczyk (1996) expandem o conceito de correspondência, demonstrando que relações lingüísticas individuais (p. ex., entre uma base e o produto de determinada operação morfológica) podem ser segmentadas em múltiplas cadeias numa língua e que cada cadeia é regulada por seu próprio conjunto de restrições de fidelidade. Em outras palavras, cada agrupamento morfológico apresenta relações de correspondência próprias, uma vez que padrões fonológicos podem variar de acordo com diferenças entre operações morfológicas: um padrão detectado num processo (p. ex. Hipocorização) pode não ocorrer em outro (p. ex. Truncamento). Para esses autores, a Gramática Universal tem o poder de propagar as relações de correspondência, levando em conta as especificidades dos processos morfológicos. Em (13), mostro como as relações de correspondência podem se multiplicar em conjuntos completos de restrições de fidelidade, tendo em vista o tipo de identidade entre duas camadas segmentais. \{MAX, DEP, IDENT-T, INTEGR, UNIFORM, LIN, ANCOR $\}$

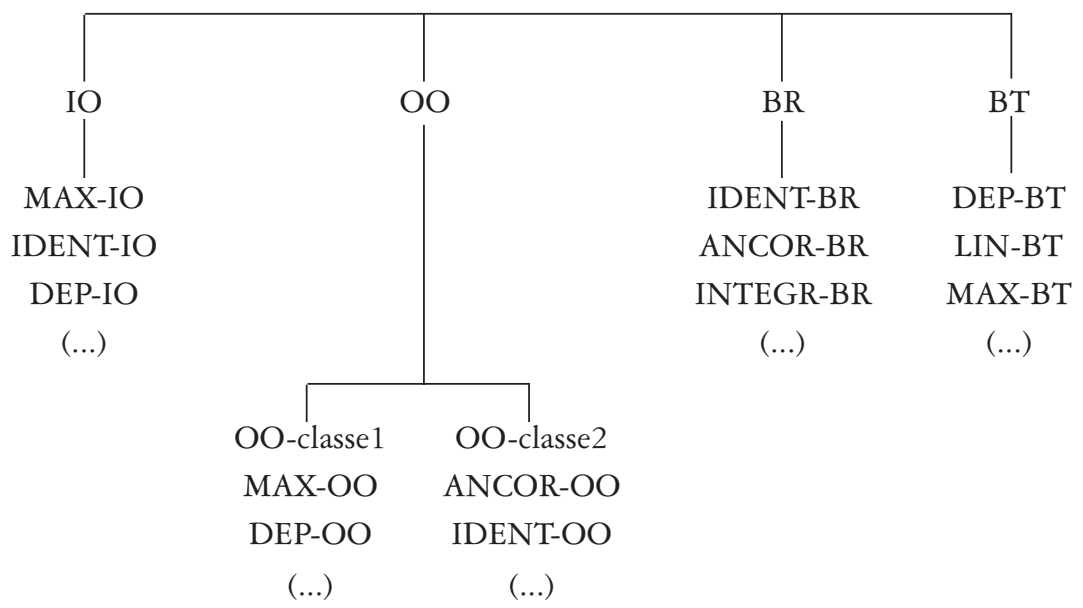

7 CONTIG (contigüidade) pode ser definida da seguinte maneira: "elementos adjacentes em S1 correspondem aos elementos adjacentes de S2. Segmentos de S1 e S2 devem manter a mesma sequiência de seus elementos correspondentes" (McCarthy \& Prince, 1995, Kager, 1999, De Lacy, 1999 e Dorigo, 2001, entre outros). Como a contigüidade/adjacência é desfeita por acréscimo, inserção ou mesmo mudança na ordem dos segmentos, não vejo motivação relevante para incluir CONTIG no rol das restrições de correspondência. As violações de CONTIG por ser monitoradas por MAX, DEP ou LIN, motivo pelo qual considero tal restrição redundante e, por isso mesmo, não-pertinente. 
Para Benua (1995), a Gramática de uma língua é avaliada por um ranking único de conjuntos completos de fidelidade (a) para todas as relações formais e (b) para todas as restrições de marcação. Como as restrições de correspondência podem ser reescritas, levando-se em conta o agrupamento(S) morfológico(S), ANCOR, IDENT-T, LIN e todas as demais propostas por McCarthy \& Prince (1995) constituem famílias de restrições. Dois restritores básicos são definidos em (14) e (15) para a relação de correspondência entre uma Base (B) e seu Reduplicante (R), mas podem ser expandidos para outras relações formais, como visualizado em (13) e reescrito entre parênteses, em (14) e (15).

(14) MAX-BR: Todo segmento de B tem um correspondente em R (ou MAX-BT todo segmento de $\mathrm{B}$ tem um correspondente em $\mathrm{T}$ ). Não pode haver apagamento de B para $\mathrm{R}$ (ou de $\mathrm{B}$ para $\mathrm{T}$ ).

(15) DEP-BR: Todo segmento de R tem um correspondente em B (ou DEP-BT todo segmento de $\mathrm{B}$ tem um correspondente em $\mathrm{T}$ ). Não pode haver inserção de $\mathrm{R}$ para $\mathrm{B}$ (ou de $\mathrm{R}$ para $\mathrm{T}$ ).

Por exemplo, uma perfeita correspondência entre B e R ocorre em casos de reduplicação total, como em 'pega-pega', 'puxa-puxa', 'pula-pula' e 'bate-bate': todos os segmentos da base verbal são copiados, satisfazendo tanto MAX-BR quanto DEP-BR. Acontece desvio nessa relação quando o reduplicante reproduz apenas parte da palavra-matriz, violando MAX-BR, como ocorre nos casos de reduplicação parcial ('Fafá', de 'Fátima' e 'Cacá', de 'Carlos'). MAX-Ba e DEP-Ba são, portanto, restritores quantitativos, uma vez que impõem mesmo número de segmentos em B (base) e a (produto da operação morfológica). Os demais restritores (08 a 12) avaliam qualitativamente a identidade entre segmentos, nas dimensões prosódica e autossegmental.

Ressaltei mais acima que, nos processos não-concatenativos, formas de base estão sujeitas a uma modificação fonológica não justificável sintagmaticamente. Nos casos de subtração morfológica, por exemplo, um segmento sofre deleção e essa perda segmental é responsável pela expressão de um conteúdo, como ocorre na Hipocorização ('Beto', por 'Roberto'; e 'Lena', por 'Marilene') e no Truncamento ('delega', por 'delegado'; e 'portuga', por 'português') - processos em que a redução é responsável pela chamada função discursiva dos processos de formação de palavras, nos termos de Basílio (1987). Na perspectiva da TC, esses pares de formas são caracteri- 
zados por uma infração de MAX, que bane qualquer tipo de apagamento. Seguindo esse raciocínio, vários tipos de restrições de fidelidade são violados em processos não-aglutinativos, como sumarizo em (16):

(16)

\begin{tabular}{|c|c|c|}
\hline $\begin{array}{c}\text { Restrição } \\
\text { Violada }\end{array}$ & Processo Morfológico & Exemplo em português \\
\hline MAX & subtração morfológica & Francisco $>$ Chico \\
\hline DEP & infixação & ---- \\
\hline IDENT-T & umlaut, ablaut, mutação & avô $>$ avó; nôvo $>$ nóva \\
\hline LIN & metátese morfológica & ---- \\
\hline INTEGR & reduplicação & bate-bate; lambe-lambe \\
\hline UNIFORM & haplologia morfológica & expulsar $>$ expulsão \\
\hline ANCOR & blend lexical & saco + picolé $=$ sacolé \\
\hline
\end{tabular}

Infrações de fidelidade são também observadas na fonologia regular, como demonstro no quadro (17), mas a natureza da violação encontrada nos processos não-concatenativos é especial. Por exemplo, a alternância vocálica do par 'novo'/'nova' é diferente da encontrada em 'colega' e 'bolota', em que a abertura da pretônica é pela motivada pela existência de uma tônica aberta (harmonia vocálica). Mesmo redundante, a alternância na raiz de 'nova' serve para expressar o conteúdo $\{$ feminino $\}$, reforçando, submorfemicamente (Mattoso Camara Jr., 1970), a marca morfológica de gênero (sufixo -a). No quadro a seguir, apresento as mesmas restrições de fidelidade vistas em (16), desta feita com os processos fonológicos que surgem a partir de suas violações.

\begin{tabular}{|c|c|c|}
\hline $\begin{array}{l}\text { Restrição } \\
\text { Violada }\end{array}$ & Processo Fonológico & Exemplo em português \\
\hline MAX & síncope & /'feyra/ $>>$ ['fe.ra] \\
\hline DEP & epêntese & /'paktU/ >> ['pa.ki.tu] \\
\hline IDENT-T & harmonia vocálica & $/ p E^{\prime} r \varepsilon b a />>$ [pe.'re.ba] \\
\hline LIN & metátese & /'tabua/ $>>$ ['taw.ba] \\
\hline INTEGR & espalhamento & $\begin{array}{c}--- \\
\end{array}$ \\
\hline UNIFORM & haplologia & $\begin{array}{c}/ \text { leytI } /+/ \mathrm{dI} /+/ \text { 'kokU } />> \\
\text { ['leydzi.'ko.pu] }\end{array}$ \\
\hline ANCOR & sândi & $\begin{array}{c}/ \text { kara } /+ \text { /amiga/ }>> \\
\text { ['ka.ra.'mi.ga] }\end{array}$ \\
\hline
\end{tabular}


Seria a Morfologia Não-Concatenativa caracterizada pelo ranking MARCAÇÃO > > FIDELIDADE, como os processos fonológicos regulares, ou um componente especial, no qual emergem efeitos de "anti-fidelidade"? O que faz os processos não-aglutinativos serem tão diferentes? Ao que tudo indica, o slogan "emergência do não-marcado" (McCarthy \& Prince, 1994) não se aplica a processos como o Truncamento e o Blend Lexical, pois formas como 'flagra' (por 'flagrante') e 'uísquerda' ('uísque' + 'esquerda') não são menos complexas estruturalmente que suas palavras-matrizes. Restrições como ONSET e NÃO-CODA não explicam satisfatoriamente a redução, no caso do Truncamento, e a fusão, no caso do Blend Lexical.

Ao estender a noção de correspondência para a dimensão O-O (Output-Output), a TC consegue diferenciar processos morfológicos não-concatenativos de processos fonológicos. Nesse último caso, distorções entre forma subjacente e forma final ocorrem numa dimensão I-O (InputOutput). Nas operações não-aglutinativas, diferenças entre as representações profunda e superficial acontecem numa dimensão O-O (OutputOutput), de um modo geral, e nas dimensões específicas de cada processo (B-R e B-T, p. ex.).

Vejamos a seguir como a TC possibilita abordar o fenômeno da Hipocorização, descrito em Gonçalves (2004) a partir de um enfoque morfoprosódico, que dá destaque a noções como moldes e circunscrições ${ }^{8}$. Nos hipocorísticos, a perda de massa fônica é motivada por restrições de tamanho prosódico a que formas plenas não se sujeitam. Dessa maneira, estruturas marcadas que aparecem no domínio de $S_{1}$ (dimensão de fidelidade input-output) podem ser barradas no domínio de $\mathrm{S}_{2}$ (domínio de identidade output-output), assumindo-se o seguinte ranking:

(18) FIDELIDADE EM S $S_{1}>>$ MARCAÇÃO $>>$ FIDELIDADE EM S

\footnotetext{
8 O que chamo de Hipocorização - processo responsável pela formação de nomes próprios diminutos - corresponde ao que Benua (1995) e outros teóricos chamam de Truncamento (Truncation). Como, em português, há diferentes processos não-concartenativos de encurtamento (Gonçalves, 2003), reservo o termo Hipocorização para a redução de antropônimos (hipocorísticos) e Truncamento para a formação de outros nomes encurtados (cf., p. ex., 'freela', por 'free lancer', e 'portuga', por 'português'). Remeto o leitor interessado nas diferenças entre Truncamento e Hipocorização para o texto de Gonçalves (2003), no qual são pormenorizados os argumentos que me levaram a considerar esses processos como distintos em português.
} 
A dimensão $\mathrm{BH}$ (Base-Hipocorístico) é uma instância específica da dimensão Output-Output (Benua, 1995). As restrições responsáveis pelo encurtamento de antropônimos são as de tamanho, uma vez que o hipocorístico tem de satisfazer exigências como as que se seguem: (a) deve constituir palavra mínima na língua e, por isso mesmo, (b) não pode apresentar mais de um pé binário. Vejam-se os dados em (19) abaixo:

\begin{tabular}{|c|c|c|}
\hline 19) Franscisco $>$ Chico & Gertrudes $>$ Tude & Isabel $>$ Bel \\
\hline Eduardo $>$ Edu & Cristina $>$ Cris & Rafael $>$ Rafa \\
\hline André $>$ Dedé & Salomé > Memé & Barnabé > Bebé \\
\hline Carlos > Cacá & Leandro $>$ Lelê & Vivian $>$ Vivi \\
\hline
\end{tabular}

Levando-se em conta que o pé básico do português é o troqueu moraico, como propõem, entre outros, Gonçalves (2004) e Massini-Cagliri (1995), hipocorísticos podem ser considerados as menores formas derivadas da língua. Condições de palavra mínima são impostas a esse tipo de processo, que bloqueia qualquer formação (a) maior que duas sílabas e (b) que não contenha pelo menos um pé trocaico, como se vê nos dados a seguir:
(20) Penélope $>*$ Nélope
Barnabé $>*$ Bé
Rosângela $>*$ Zângela
Dinorá $>*$ Rá
Américo $>*$ Mérico
Salomé $>$ *Mé
Eurípedes $>*$ Rípedes
André $>*$ Dé

Como são palavras mínimas, hipocorísticos emergem quando condições sobre a palavra prosódica (PWd) são respeitadas. Essas formas encurtadas são, em português, minimamente bimoraicas e maximamente dissilábicas e, por isso, a restrição PÉ-BIM, formulada em (21a), deve ser sempre obedecida. Além de PÉ-BIM, outros restritores de palavra mínima também exercem pressão para que o output não apresente mais de duas sílabas: ANALISE- $\sigma$ e TODO-PÉ(D).

(21) Restritores de Palavra Prosódica
(a) PÉ-BIM (PÉ BIMoraico): Todos os pés $(\Sigma)$ tem de ser bimoraicos $([\mu \mu] \Sigma)$, tenham eles uma única sílaba pesada $([\sigma \mu \mu] \Sigma)$ ou duas leves $([\sigma \mu \sigma \mu] \Sigma)$.
(b) ANALISE- $\sigma$ (Analise sílabas): Todas as sílabas $(\Sigma)$ devem ser incorporadas a pés $(\Sigma)$.
(c) TODO-PÉ(D) (Pés à direita): Todos os pés $(\Sigma)$ devem permanecer na posi- ção de final de palavra prosódica (PWd).


Uma perfeita satisfação aos três restritores apresentados em (21) só é possível quando a palavra prosódica apresenta um único pé bimoraicio. Se PÉ-BIM demanda que pés tenham duas moras, ANALISE- $\sigma$ proíbe a existência de sílabas não-licienciadas por pés. (21c) é uma restrição de alinhamento (McCarthy \& Prince, 1993) que governa a posição dos pés $(\Sigma)$ no interior da palavra prosódica. Uma vez que impõe alinhamento entre $\Sigma$ s e PWds, cada pé é avaliado em relação à distância que o separa da margem direita da palavra prosódica. Assumindo-se a hierarquia PÉ-BIM $>>$ ANALISE- $\sigma>>$ TODO-PÉ(D), o output ótimo não pode apresentar mais de duas sílabas leves, como se observa no Tableau abaixo:

(22)

\begin{tabular}{|c|c|c|c|}
\hline Input: / $\sigma \sigma \sigma /$ & $\begin{array}{l}\text { PÉ- } \\
\text { BIM }\end{array}$ & $\begin{array}{l}\text { ANÁ- } \\
\text { LISE- } \sigma\end{array}$ & $\begin{array}{l}\text { TODO- } \\
\text { PÉ(D) }\end{array}$ \\
\hline a. $\left[\left(\sigma_{\mu \mu}\right]_{\Sigma_{2}}\left(\sigma_{\mu} \sigma_{\mu}\right)_{\Sigma_{1}}\right]_{\mathrm{Pwd}}$ & & & $! \Sigma 2=\sigma \sigma$ \\
\hline b. $\left[\left(\sigma_{\mu} \sigma_{\mu}\right)_{\Sigma_{2}}\left(\sigma_{\mu \mu}\right)_{\Sigma_{1}}\right]_{\text {pud }}$ & & & $! \Sigma 2=\sigma$ \\
\hline c. $\left[\left(\sigma_{\mu} \sigma_{\mu}\right)_{\Sigma_{2}}\left(\sigma_{\mu}\right)_{\Sigma_{1}}\right]_{P_{w d}}$ & $* !$ & & $! \Sigma 2=\sigma$ \\
\hline d. $\left[\left(\sigma_{\mu \mu}\right)_{\Sigma_{3}}\left(\sigma_{\mu \mu}\right)_{\Sigma_{2}}\left(\sigma_{\mu \mu}\right)_{\Sigma_{1}}\right]_{\mathrm{Pwd}}$ & & & $! \Sigma 3=\sigma \sigma ; \Sigma 2=\sigma$ \\
\hline e. $\left[\left(\sigma_{u}\right)_{\Sigma_{2}}\left(\sigma_{u} \sigma_{u}\right)_{\Sigma_{1}}\right]_{\mathrm{Pud}_{\mathrm{d}}}$ & $* !$ & & $! \Sigma 2=\sigma \sigma$ \\
\hline f. $\left[\sigma_{\mu}\left(\sigma_{\mu} \sigma_{\mu}\right)_{\Sigma_{1}}\right]_{\mathrm{Pwd}}$ & & $* !$ & \\
\hline g. $\left.\left[\left(\sigma_{\mu} \sigma_{\mu}\right)_{\Sigma_{1}} \sigma_{\mu}\right)\right]_{\mathrm{pwd}}$ & & $* !$ & \\
\hline h. $\left[\left(\sigma_{\mu} \sigma_{\mu}\right)_{\Sigma_{1}}\right]_{\mathrm{Pwd}}$ & & & \\
\hline i. $\left[\left(\sigma_{\mu}\right)_{\Sigma_{1}}\right]_{\mathrm{Pwd}}$ & $* !$ & & \\
\hline j. $\quad\left[\left(\sigma_{\mu \mu}\right)_{\Sigma_{1}}\right]_{\mathrm{Pwd}_{\mathrm{wd}}}$ & & & \\
\hline 1. $\left[\sigma_{\mu}\left(\sigma_{\mu \mu}\right)_{\Sigma_{1}}\right]_{\mathrm{Pwd}}$ & & $* !$ & \\
\hline
\end{tabular}

Pelo Tableau, pode-se constatar que qualquer candidato com mais de duas sílabas é mal-sucedido, seja por não respeitar a integração de sílabas a pés (f, $g, 1)$, seja por não alinhar algum pé com a margem direita da palavra prosódica (a, b, c, d, e). A solução mais viável para passar pelo crivo de tais restrições é diminuir o número de sílabas, como fazem os candidatos (h), (i), (j), e (l). No entanto, essa redução deve ser consistente com a condição de que os pés sejam necessariamente bimoraicos $(\llbracket \mu \mu] \Sigma)$. Por essa razão, o candidato (i), embora menor que o input, com uma única sílaba leve, é sumariamente eliminado por PÉ-BIM, já que a PWd é constituída de um pé monomoraico. A forma (l) atende à imposição de PÉ-BIM, mas é 
eliminada porque a primeira sílaba não foi analisada em pés. Restaram, portanto, apenas dois candidatos: (h) e (j), ambos com um só pé bimoraico, sendo o primeiro constituído de duas sílabas leves e o segundo de uma única sílaba pesada.

O encurtamento da forma lexical de base é inevitável quando restritores de palavra prosódica dominam restrições de fidelidade. Assim, para haver Hipocorização, alguma perda segmental necessariamente ocorre e, em conseqüência, formas inteiramente fiéis ao input jamais serão consideradas hipocorísticas.

Neste artigo, vou me restringir ao exame da "Hipocorização do Tipo A" (exemplos da primeira linha de 19), considerada mais produtiva e padrão default para a formação de hipocorísticos no português do Brasil (Gonçalves, 2004). A principal característica das formas reduzidas por esse modelo é a manutenção do acento lexical das palavras-matrizes: a parte reproduzida é justamente aquela que contém a sílaba proeminente, que não pode ser removida de sua posição original. Vejam-se mais dados em (23):

\begin{tabular}{|c|c|c|}
\hline 3) Felipe $>$ Lipe & Raquel > Quel & Alexandre $>$ Xande \\
\hline$>$ Tonho & Isabel $>\mathrm{Bel}$ & Edivaldo $>$ Valdo \\
\hline Augusto $>$ Guto & Marimar $>$ Mar & Fernando $>$ Nando \\
\hline Filomena $>$ Mena & Nicolau $>$ Lau & Reginaldo \\
\hline
\end{tabular}

$\mathrm{Na}$ primeira coluna, as formações apresentam estrutura 'CV.CV (pé dissilábico com cabeça à esquerda). $\mathrm{Na}$ segunda, os nomes têm padrão silábico 'CVC (pé monossilábico). Nesse grupo, a palavra-matriz é oxítona e a sílaba final é travada por uma consoante ('Isabel') ou por um glide ('Nicolau'). A terceira coluna é a dos pés trocaico-dissilábicos com sílaba proeminente pesada (estrutura 'CVC.CV). Hipocorísticos podem ser analisados como moldes que copiam a circunscrição positiva das palavrasmatrizes (Gonçalves, 2004), mas também podem ser descritos pela OT, através de restritores de palavra prosódica, de fidelidade e de marcação.

No caso do português, a fidelidade ao input se manifesta na sensibilidade à cabeça de palavra prosódica (PWd), uma vez que o hipocorístico copia a sílaba tônica da palavra-matriz oxítona (coluna 2, de 23) e, no caso de paroxítonas e proparoxítonas, a única postônica (colunas 1 e 3) e a pos- 
tônica ajustada ao molde, respectivamente ${ }^{9}$. A restrição abaixo formulada dá conta da correspondência do hipocorístico para com a cabeça de PWd:

(24) $\mathrm{DEP}(\mathrm{H})$-CABEÇA-PWd $(\mathrm{FB})$ - Dependência do Hipocorís-tico $(\mathrm{H})$ à cabeça de palavra prosódica (PWd) da Forma de Base (FB):

Cada elemento contido na cabeça prosódica de $\mathrm{S}_{2}(\mathrm{H})$ deve ter um correspondente em $\mathrm{S}_{1}$ (palavra-matriz). Não pode haver inserção de segmentos da cabeça de PWd da palavra-matriz para a cabeça de PWd do hipocorístico.

Para Benua (1995, P. 122), hipocorísticos não estabelecem relação de correspondência com o input. Se, por um lado, MAX-IO é sempre ignorada, levando o hipocorístico a ser fatalmente menor que a forma de base, por outro, há forte ligação do hipocorístico com o pé da palavra-matriz no qual se manifesta o acento lexical (dados de 23). Desse modo, a afirmação de Benua (op. cit.) não se mostra inteiramente adequada para o português, pois o hipocorístico certamente depende do input. A restrição formulada em (24) assegura que o encurtamento não seja arbitrário, permitindo a deleção de qualquer segmento da palavra-matriz. É bem verdade que o apagamento é o preço que se paga pela minimização (Benua, 1995: 123), mas essa redução não é fortuita, posto que governada por uma restrição de fidelidade I-O (Input-Output). O ranking abaixo proposto leva ao encurtamento, mas garante mínima fidelidade à palavra-matriz:

(25) PÉ-BIM $>>$ ANALISE-s $>>$ TODO-PÉ(D) $>>$ $\mathrm{DEP}(\mathrm{H})-\mathrm{CABEÇA-PWd}(\mathrm{FB})>>$ MAX-IO

No meu entender, hipocorísticos tendem a ser dependentes tanto do input, na satisfação a $\mathrm{DEP}(\mathrm{H})$-CABEÇA-PWd(FB), quanto do output, na obediência a restrições que não pressupõem qualquer mapeamento inputoutput. De acordo com Benua (1995, p. 122), há, na Hipocorização, um mecanismo transderivacional, pois uma base (B) finaliza a formação do

\footnotetext{
9 Nos prenomes proparoxítonos, a cópia poderia levar a um hipocorístico constituído de três sílabas ('Rosângela' > *'Zângela'), mas a condição de bissilabicidade (Gonçalves, 2004) leva a base a se ajustar ao molde - um pé bimoraico -, fazendo com que a primeira vogal postônica seja apagada ('Zanza'). Outros dados que comprovam ajuste das proparoxítonas ao molde são os seguintes, entre outros: 'Débora' > 'Deba', 'Rômulo' > 'Romo' e 'Austregésilo' > 'Geso'.
} 
hipocorístico $(\mathrm{H})$, conforme se visualiza em (26). Essa proposta dá conta de um fato extremamente interessante em português (Gonçalves, 2004): o surgimento de um tepe à esquerda do pé que os restritores de palavra prosódica e $\mathrm{DEP}(\mathrm{H})-\mathrm{CABEÇA-PWd(FB)} \mathrm{selecionam.}$

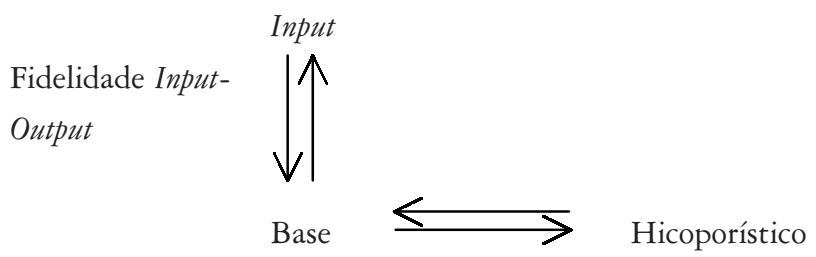

Fidelidade Output-Output (BH)

Nos dados de (27a), um tepe aparece como onset inicial do pé utilizado para formar hipocorísticos em português - o pé bimoraico, formado da esquerda para a direita da palavra-matriz (Gonçalves, 2004). A impossibilidade de o português apresentar/r/ em início de palavras força a utilização de uma estratégia de reparo para substituir o segmento indevido e preencher essa posição, já que não existem hipocorísticos iniciados por vogal em nossa língua, como se observa nos exemplos de (27b):
(27) (a) Murilo > Lilo Nazareno $>$ Neno Florinda $>$ Dinda

(b) $\begin{array}{r}\text { Eduardo }>\text { Dado } \\ \text { Mariana }>\text { Nana } \\ \text { Joelma }>\text { Melma }\end{array}$

Esses casos constituem evidência empírica em favor de uma correspondência output-output, uma vez que o hipocorístico realmente parece depender de uma base, no output. A avaliação de 'Nazareno' pelas restrições até então apresentadas levaria a uma representação final que, na verdade, não é hipocorístico do antropônimo em questão: equivale ao molde, numa análise derivacional. $\mathrm{O}$ tableau abaixo, no qual o acento agudo sobre as vogais indica posição da cabeça prosódica, possibilita visualizar melhor esse fato: 


\begin{tabular}{|c|c|c|c|c|c|}
\hline Input: /na.za.ré.no/ & $\begin{array}{l}\text { PÉ- } \\
\text { BIM }\end{array}$ & $\begin{array}{l}\text { ANÁ- } \\
\text { LISE }\end{array}$ & $\begin{array}{l}\text { TODO- } \\
\text { PÉ(D) }\end{array}$ & $\begin{array}{c}\mathrm{DEP}(\mathrm{H}) \\
(\mathrm{FB})\end{array}$ & $\begin{array}{c}\text { MAX- } \\
\text { IO } \\
\end{array}$ \\
\hline a. $\left[(\text { ná.za })_{\Sigma_{2}}(\text { ré.no })_{\Sigma_{1}}\right]_{\mathrm{Pwd}}$ & & & $! \Sigma 2=\sigma \sigma$ & & \\
\hline b. $\left[(\mathrm{za})_{\Sigma_{2}}(\text { ré.no })_{\Sigma_{1}}\right]_{\mathrm{Pwd}_{\mathrm{wd}}}$ & $* !$ & & $\Sigma 2=\sigma \sigma$ & & $* *$ \\
\hline c. $\left[\mathrm{za}(\text { ré.no) })_{\Sigma_{1}}\right]_{\mathrm{Pwd}}$ & & $* !$ & & & $* *$ \\
\hline d. $\left[(\text { ná.za })_{\Sigma_{2}}\right]_{\mathrm{Pwd}_{\mathrm{w}}}$ & & & & $*$ & $* * * *$ \\
\hline e. $\left[(\text { ré.no })_{\Sigma_{1}}\right]_{\mathrm{Pwd}_{\mathrm{w}}}$ & & & & & $* * * *$ \\
\hline f. $\left.\quad[\text { (na.zá })_{\Sigma_{1}}\right]_{\mathrm{Pwd}_{\mathrm{w}}}$ & & & & * & $* * * *$ \\
\hline g. $\left[(\text { re.nó })_{\Sigma_{1}}\right]_{\mathrm{Pwd}_{\mathrm{wd}}}$ & & & & $*$ & $* * * *$ \\
\hline h. $\left[(\text { ré })_{\Sigma_{1}}\right]_{\mathrm{Pwd}_{\mathrm{w}}}$ & $* !$ & & & & $* * * * * *$ \\
\hline
\end{tabular}

Os três primeiros candidatos apresentam mais de duas sílabas e, por isso mesmo, não chegam sequer a ser avaliados por $\mathrm{DEP}(\mathrm{H})$-CABEÇAPWd(FB): são eliminados pelos restritores de PWd. O último, embora menor que o input, não obtém êxito porque não contém um pé bimoraico. As formas (d), (e), (f), e (g) se submetem à inspeção pelas restrições de fidelidade (duas últimas colunas). Uma vez que quatro segmentos do input foram apagados, todos os concorrentes violam MAX-IO da mesma maneira, mas essa restrição é ranqueda mais baixo, não sendo capaz de arbitrar sobre a seleção da melhor forma de output. A escolha cabe a $\operatorname{DEP}(\mathrm{H})$ CABEÇA-PWd(FB), que seleciona (e). Essa forma, no entanto, não corresponde ao hipocorístico de 'Nazareno', 'Neno', uma vez que o tepe foi substituído por uma nasal - a mesma que aparece no onset da segunda sílaba. Por que isso acontece? Qual a razão para substituir um segmento do input, já que as restrições de tamanho prosódico autorizam a forma ['re.no], que se mantém fiel à cabeça de palavra prosódica, em 'Nazareno'?

Em termos derivacionais, a substituição do tepe seria conseqüência do PPE (Princípio de Preservação de Estrutura - Kiparsky, 1982), segundo o qual processos morfológicos não podem operar com traços não-distintivos nem criar estruturas em desacordo com os padrões prosódicos básicos da língua ${ }^{10}$. Submetendo-se ao PPE, a Hipocorização repara formas com

\footnotetext{
10 Em termos de Fonologia Lexical (cf. Kiparsky, 1982), pode-se admitir que a Hipocorização constitui processo lexical, uma vez que os hipocorísticos permitem o acréscimo de sufixos (cf. 'Leninha', de 'Marilena', e 'Lipão', de 'Felipe'), além de se submeterem ao PPE.
} 
segmentos que não podem aparecer na periferia esquerda do constituinte prosódico PWd. Uma restrição sobre onsets pode resolver esse problema, mas tal imposição de modo algum pressupõe relação com o input, pois os onsets de 'Nazareno' estão em conformidade com o PPE. A restrição formulada abaixo parece se dirigir a uma forma, que, seja qual for o motivo, acabou se iniciando por um tepe:

(29) *[r ${ }_{\text {PWd }}$ - Não pode existir palavra prosódica iniciada por [r] Tepes são proibidos no início de palavras prosódicas (PWd).

Implicitamente, a restrição formulada em (29) faz referência a uma base, já que a palavra-matriz ('Nazareno') não apresenta tepes em início de PWd. No entanto, a condição (29) é inteiramente necessária para barrar o candidato (28e), selecionado como output ótimo tanto pelos restritores de PWd quanto pela restrição de fidelidade $\operatorname{DEP}(\mathrm{H})$-CABEÇA-PWd(FB). Se incluirmos (29) no Tableau, a forma ['re.no] será eliminada, mas outro problema surge: qual será, então, o verdadeiro hipocorístico de 'Nazareno'? Qualquer forma de output que venha a substituir o onset [r] incorrerá numa violação a mais de fidelidade ao input: IDENT-T, que desautoriza qualquer modificação de traços do domínio I para o domínio O. Se, por um lado, essa violação ocorre para satisfazer $*\left[\mathrm{r}_{\mathrm{PWd}}\right.$, ranqueada mais alto, por outro, tem como conseqüência maior sacrifício da relação de correspondência entre as representações subjacente e de superfície.

A inclusão de ONSET (sílabas devem ter ataques) na hierarquia, embora necessária, não resolve o problema ora em discussão, pois o hipocorístico apresenta esse constituinte. Aliás, a própria atuação de ONSET, que impede formas como *'Elma' (de 'Joelma') e *'Ana' (de 'Mariana'), constitui prova de que a Hipocorização realmente atua numa dimensão de correspondência output-output, já que o preenchimento do ataque, em prenomes como 'Eduardo' e 'Mariana', só faz sentido quando restritores de palavra prosódica exercem pressão para que a forma encurte. De qualquer modo, ONSET e *[r ${ }_{\text {PWd }}$, que são, na verdade, restrições de marcação, devem dominar IDENT-T e MAX, que são restrições de correspondência, para que seja escolhido o output correto.

A restrição formulada em (30) impõe coincidência entre os onsets de PWds constituídas de duas sílabas, mas seus efeitos só são visíveis quando 
a penúltima sílaba do antropônimo se inicia por um tepe, como em 'Murilo' e 'Florinda', ou não apresenta ataque, como em 'Eduardo' e 'Joelma'. Dessa maneira, (30), também uma restrição de marcação, tem de ser ranqueada abaixo de ONSET e *[r ${ }_{\mathrm{PWd}}$ :

(30) $\left[\mathrm{ONSET}_{\sigma 1}=\mathrm{ONSET}_{\sigma 2}\right]_{\mathrm{PWW}_{\mathrm{d}}}-\mathrm{O}$ ataque da $\sigma 1$ é igual ao da $\sigma 2$ quando $[\sigma \sigma]_{\mathrm{PWd}}$ : Numa palavra prosódica dissilábica, o ataque da primeira sílaba deve ser idêntico ao ataque da segunda sílaba ${ }^{11}$.

Um ranking completo é proposto em (31) a seguir. Observe-se que ONSET e *[r ${ }_{\text {PWd }}$ devem ser ranqueadas acima de IDENT-T e [ONSET $_{\sigma 1}=$ ONSET $\left._{\sigma 2}\right]_{\mathrm{PWd}}$, já que a cópia do segundo onset, em dados como 'Murilio' > 'Lilo' e 'Mariana' > 'Nana', prejudica a identidade de traços entre palavra-matriz e hipocorístico, mas é a solução encontrada para atender ONSET ou * $\left[\mathrm{r}_{\mathrm{PWd}}\right.$. IDENT-T deve dominar [ONSET $_{\sigma 1}=$ ONSET $\left._{\sigma 2}\right]_{\mathrm{PWd}}$, para que formas como 'Lipe' ('Felipe') e 'Xande' ('Alexandre') sejam melhores que *'Pipe' e *'Dande', cujos onsets têm segmentos idênticos. MAX-IO aparece no final da hierarquia, pois é violada sempre, por mais que o hipocorístico se aproxime da palavra-matriz.

(31) PÉ-BIM $>>$ ANALISE- $\sigma>>$ TODO-PÉ(D) $>$ DEP(H)-CABEÇA-
PWd $(\mathrm{FB})>>$ ONSET, $*[\mathrm{r} \quad$ PWd $>$ IDENT-T $>>$
[ONSET $_{\sigma 1}=$ ONSET $\left._{\sigma 2}\right]_{\mathrm{PWd}}>>$ MAX-IO

No Tableau abaixo, mostro a atuação de AVAL na seleção do hipocorístico de 'Nazareno', 'Marilena' e 'Mariana', nesta ordem. Com o propósito de simplificar a análise, listo apenas seis candidatos para cada input, desconsiderando outras formas que seriam fatalmente barradas pelos restritores de PWd. Em todos os casos, a seleção compete às restrições ranqueadas mais baixo, como IDENT-T e ONSET ${ }_{\sigma 1}=$ ONSET $\left._{\sigma 2}\right\rfloor_{\mathrm{PWd}}$ :

\footnotetext{
11 A restrição proposta em (30) encontra suporte também em dados de aquisição da linguagem, uma vez que crianças tendem a utilizar essa estratégia na tentativa de reproduzir a fala adulta: 'copo' é realizado 'popo' e 'prato', 'tato'.
} 
(32)

\begin{tabular}{|c|c|c|c|c|c|c|c|c|c|}
\hline & PÉ & $\mathrm{AN}$ & $\begin{array}{l}\text { T- } \\
\text { PÉ }\end{array}$ & DEP & ONS & $*[\mathrm{r}$ & ID & $\begin{array}{c}{\left[\mathrm{O}_{1}=\right.} \\
\left.\mathrm{O}_{2}\right]\end{array}$ & MAX \\
\hline \multicolumn{10}{|l|}{$I:$ /nazaréno/ } \\
\hline a. [(ré.no $)]$ & & & & & & $* !$ & & & $* * * *$ \\
\hline b. $[($ na.za $)]$ & & & & $* !$ & & & & & $* * * *$ \\
\hline c. $[($ dé.no $)]$ & & & & & & & $*$ & $* !$ & $* * * *$ \\
\hline d. $[$ (né) $]$ & $* !$ & & & & & & & & $* * * * * *$ \\
\hline e. $\{$ za (ré.no)] & & $* !$ & & & & & & & $* *$ \\
\hline f. $[$ (né.no $)]$ ( & & & & & & & $*$ & & $* * * *$ \\
\hline \multicolumn{10}{|l|}{$I:$ /mariléna/ } \\
\hline a. $[($ má.ri $)]$ & & & & $* !$ & & & & & ***** \\
\hline b. [(né.na) $]$ & & & & & & & $* !$ & & $* * * *$ \\
\hline c. $[($ lé.na $)]$ & & & & & & & & $*$ & $* * * *$ \\
\hline d. [ri (lé.na)] & & $* !$ & & & & $*$ & & & $* *$ \\
\hline e. $[$ (mé.na $)]$ & & & & & & & $* !$ & & $* * * *$ \\
\hline f. $[(\mathrm{ma})($ lé.na $)]$ & $* !$ & & $*$ & & & & & & $* *$ \\
\hline \multicolumn{10}{|l|}{$I:$ /mariána/ } \\
\hline a. $[(a ́ . n a)]$ & & & & & $* !$ & & & & $* * * *$ \\
\hline b. [(lá.na) $]$ & & & & & & & $*$ & $* !$ & $* * * *$ \\
\hline c. $[($ ri $)(a ́ . n a)]$ & $* !$ & & $*$ & & $*$ & $*$ & & & $* *$ \\
\hline d. $[$ (na.na) $])$ & & & & & & & $*$ & & $* * * *$ \\
\hline e. $[$ (má.na $)]$ & & & & & & & $*$ & $* !$ & $* * * *$ \\
\hline f. [(má.ri) $]$ & & & & $* !$ & & & & & \\
\hline
\end{tabular}

Comecemos pelo input 'Nazareno'. Como se vê, três candidatos ficaram no páreo, após avaliação pelos restritores de palavra prosódica e por $\operatorname{DEP}(\mathrm{H})-C A B E C ̧ A-P W d(F B)$ : (a), (c) e (f). O primeiro acaba sendo eliminado pela restrição estrutural que proíbe palavras iniciadas por tepe

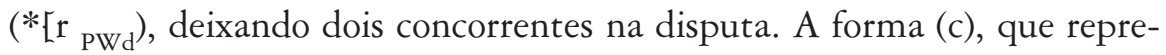
senta qualquer candidato com onset diferente de $/ \mathrm{r} / \mathrm{e} / \mathrm{n} /$, não é fiel à especificação de traços do input tanto quanto seu principal oponente - (f) - mas não consegue superar o rival na avaliação feita pela restrição imediatamente dominada por IDENT. Uma vez que os dois onsets de 'Neno' são idênticos, essa forma é escolhida como output de 'Nazareno', sendo melhor que 'Deno' (ou 'Meno', 'Leno' e 'Reno', entre outros) por obedecer [ONSET $\left._{\sigma 1}=\mathrm{ONSET}_{\sigma 2}\right]_{\mathrm{PWd}}$. No que diz respeito a 'Marilena', o candidato que mantém a consoante do input (c) é melhor que a forma que copia a consoante da segunda sílaba (b). Nesse caso, IDENT é responsável pela escolha, haja vista que ser fiel à forma de base é mais importante que 
promover a igualdade de onsets. Por fim, analisemos o input 'Mariana'. A forma mais fiel (a) não consegue passar pelo crivo de ONSET, pois sua primeira sílaba não tem ataque. Há uma disputa acirrada entre três competidores - (b), (d) e (e) - que violam uma vez IDENT, preenchendo o ataque da sílaba 1 . Desses três, apenas o segundo (d) consegue atender à ordem imposta por [ONSET $\left._{\sigma 1}=\mathrm{ONSET}_{\sigma 2}\right]_{\mathrm{PWd}}$, promovendo a igualdade de onsets no nível da palavra prosódica. Com efeito, 'Nana' é escolhido como output de 'Mariana', muito embora acrescente uma consoante à esquerda do pé bimoraico localizado à direita da palavra-matriz.

Através do Tableau (32), fica clara a dominância das restrições de marcação sobre as de identidade: o output só consegue ser mais fiel ao input quando restritores de onset são obedecidos. Esses restritores, no entanto, fazem referência implícita a uma base, já que se voltam para formas que parecem independentes do input. ONSET $\left.{ }_{\sigma 1}=\mathrm{ONSET}_{\sigma 2}\right]_{\mathrm{PWd}}$, por exemplo, focaliza formas que apresentam o tamanho de uma palavra prosódica mínima, pressupondo avaliação de candidatos que apresentem apenas duas sílabas.

No domínio de $\mathrm{S}_{1}$ (antropônimo), aparecem estruturas marcadas (existência de sílabas sem ataque, pés monomoraicos e sílabas não-integradas a pés) que são simplesmente proibidas no domínio de $\mathrm{S}_{2}$ (hipocorístico). Sem dúvida alguma, há uma semelhança entre Hipocorização e estágios iniciais de aquisição da linguagem (seção 1), uma vez que, em ambos os casos, MARCAÇÃO domina FIDELIDADE. Com a Teoria da Correspondência, é possível distinguir essa situação de dominância: as restrições de fidelidade subordinadas na Hipocorização não são as mesmas subordinadas nos primeiros estágios de aquisição. Formas não-marcadas da linguagem infantil resultam da dominância das restrições de marcação sobre as de fidelidade entre um input (a fala do adulto) e um output (a fala da criança), enquanto as que caracterizam hipocorísticos resultam de um ranqueamento similar, mas distinto, uma vez que as condições de fidelidade dominadas não são aquelas entre um input e um output, mas entre duas formas de output - a base (B) e o hipocorístico (H) propriamente dito, como se vê em (33).

(33) MARCAÇ̃̃̃O >> FIDELIDADE I-O :: Aquisição MARCAÇÃO > > FIDELIDADE O-O :: Hipocorização

Uma análise sobre o papel das restrições na emergência de hipocorísticos ótimos, portanto, dificilmente se sustentaria no paradigma da Teoria 
da Otimalidade Clássica (Prince \& Smolensky, 1993). Como não há relação direta de identidade entre um input e um output, a Teoria da Correspondência (McCarthy \& Prince, 1995; Benua, 1995) - que prevê atuação de um conjunto de restrições de fidelidade entre outputs - justifica-se como modelo paralelista mais adequado para lidar com fenômenos como esse.

O Truncamento, outro processo não-concatenativo de encurtamento (Gonçalves, 2003), também pode ser explicado pelo ranking FIDELIDADE $>>$ MARCAÇÃO $>>$ FIDELIDADE. Como se vê em (34), construções truncadas reproduzem parte da base, mas, ao contrário da Hipocorização, também se manifestam com o acréscimo de uma vogal final nem sempre existente na palavra-matriz. A vogal -a funciona, pois, como uma espécie de afixo de Truncamento.
(34) japa (japonês)
sapa (sapatão)
trava (travesti)
comuna (comunista)
sarja (sargento)
vagaba (vagabunda)
frila (free-lancer)
granfa(grã-fino)
malcra (mal-criado)

Com base na Morfologia Prosódica, Gonçalves (2003) mostra que a circunscrição mapeia uma seqüência que não aparecerá na forma truncada. Em todos os casos, forma-se um pé binário, da esquerda para a direita, do qual será aproveitado somente o primeiro onset que, alinhado à vogal -a, constituirá a última sílaba da palavra braquissemizada. Dessa forma, a circunscrição é negativa (McCarthy, 1986), pois o conteúdo segmental fora do domínio é o que será efetivamente aproveitado no Truncamento, como se pode observar em (35).

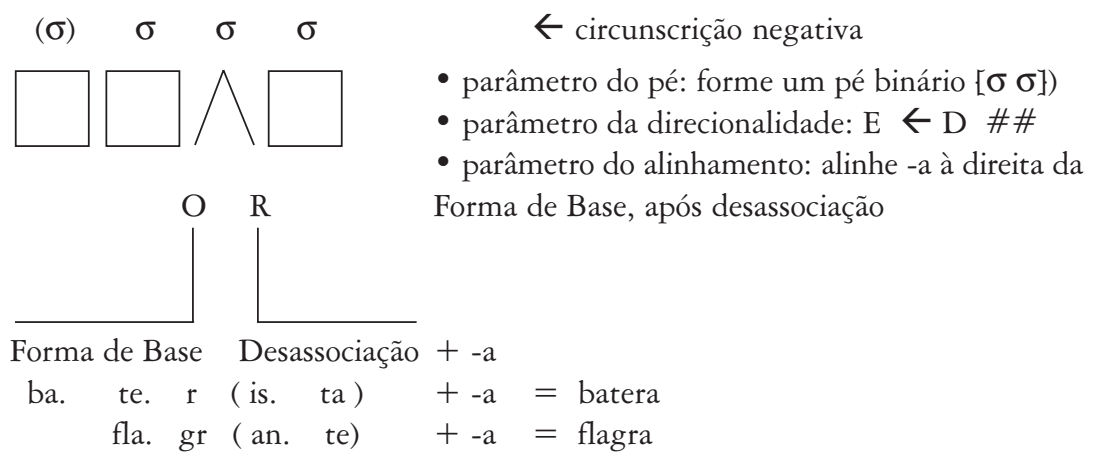


Como se pode perceber, a noção de 'palavra não-marcada' (Benua, 1995) não pode ser aplicada com sucesso à análise do Truncamento, uma vez que o produto nem sempre apresenta a mesma configuração prosódica. Uma vez que são formados dissílabos ('flagra') ou trissílabos ('batera'), condições de tamanho, como ANALISE- $\sigma$, podem ser violadas. Além disso, não há, como na Hipocorização, fidelidade à cabeça de palavra prosódica, pois o Truncamento ignora a pauta acentual da palavra-matriz, atuando de modo semelhante em oxítonas ('japonês' > 'japa'), paroxítonas ('vagabunda' $>$ 'vagaba') e proparoxítonas ('salafrário' $>$ 'salafra').

A análise proposta em (36) sugere que o Truncamento é governado por restrições de identidade Output-Output, na correspondência entre a forma truncada e a sua base. Em (36), o sufixo -a é o único elemento plenamente especificado no Input, sendo TRUNC um morfema vazio, cujo conteúdo segmental é regido pela restrição de identidade MAX-BT (todos os elementos da (B)ase devem aparecer no (T)runcamento). Portanto, MAX-IO, só será violada quando o sufixo -a, único segmento com especificação no input, estiver ausente no output.

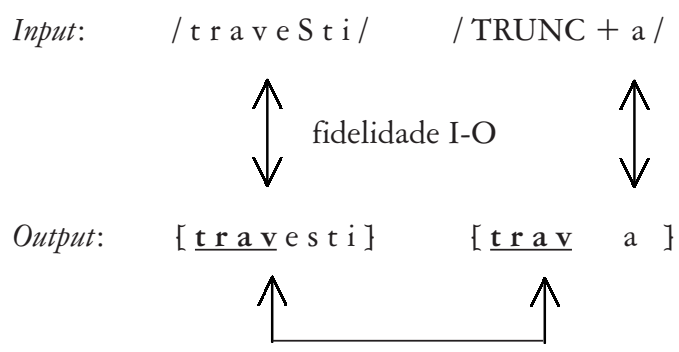

fidelidade BT

Resaltei mais acima que MAX-IO é categoricamente violada na Hipocorização, ocupando lugar menos privilegiado na hierarquia. Isso acontece porque não existe qualquer tipo de especificação segmental no input: não há marca morfológica associada ao morfema de Hipocorização. No Truncamento, ao contrário, MAX-IO constitui restrição importante, uma vez que -a, um sufixo, está presente no input. Candidatos sem esse constituinte morfológico cometem uma grave infração de fidelidade e, por isso mesmo, devem ser sumariamente eliminados. Em outras palavras, formas sem -a 
não podem ser consideradas braquissêmicas, em decorrência de TRUNC, o morfema vazio de Truncamento, alinhar-se à esquerda desse sufixo.

Há outras diferenças entre hipocorísticos e truncamentos, desta feita levando-se em conta a atuação dos restritores de palavra prosódica. Como todos os truncamentos são paroxítonos e não podem apresentar mais de três sílabas, TODO-PÉ(D) exerce pressão para que as formas reduzidas não apresentem mais de um pé. No entanto, ANALISE- $\sigma$, que milita contra a existência de sílabas não integradas a pés, tende a ser violada quando a palavra-matriz é polissilábica. Resultam dessa violação formas encurtadas com mais de duas sílabas, fazendo com que o Truncamento não constitua processo de formação de palavras mínimas, como a Hipocorização. $\mathrm{O}$ ranking abaixo proposto assegura que truncamentos sejam minimamente dissilábicos e maximamente trissilábicos em português.

$$
\text { MAX-IO }>>\text { TODO-PÉ(D) }>>\text { MAX-BT }>>\text { ANALISE- } \sigma
$$

No Tableau abaixo, mostro os efeitos de AVAL na seleção do truncamento de 'vestibular'. Como se vê, a forma que melhor atende a MAX-BT, 'vestibula', não consegue passar pelo crivo de TODO-PÉ(D), haja vista apresentar dois pés trocaicos. Os candidatos (a) e (b) são infiéis ao input, violando MAX-IO, por não apresentarem correspondente para o sufixo -a, e são imediatamente excluídos da disputa. Apenas dois concorrentes permanecem no páreo: (d) e (e). Se ANALISE- $\sigma$ fosse ranqueada acima de MAX-BT, como ocorre na Hipocorização, a forma dissilábica seria a vencedora. No caso do Truncamento, entretanto, ser mais fiel à base é mais importante que formar palavras mínimas. Por isso, o candidato que melhor satisfaz MAX-BT (d) acaba suplantando o principal oponente (e), mesmo com o custo de apresentar uma sílaba desgarrada.

\begin{tabular}{|l|c|c|c|c|}
\hline $\begin{array}{l}\text { Base: [(ves.ti).(bu.lar) } \\
\text { Input: /TRUNC + a/ }\end{array}$ & $\begin{array}{c}\text { MAX- } \\
\text { IO }\end{array}$ & $\begin{array}{c}\text { TODO- } \\
\text { PE(D) }\end{array}$ & MAX-BT & $\begin{array}{c}\text { ANÁ- } \\
\text { LISE }\end{array}$ \\
\hline a. [(vés.ti) (bú.lo)] & $* !$ & $* !$ & a r & \\
\hline b. [ ves (tí.bo)] & $* !$ & & $\mathrm{u} \mathrm{a} \mathrm{a} \mathrm{r}$ & ves \\
\hline c. [(vés.ti) (bú.la) & & $* !$ & $\mathrm{r}$ & \\
\hline d. [ves (tí.ba)] & & & $\mathrm{u} \mathrm{l} \mathrm{a} \mathrm{r}$ & ves \\
\hline e. [ (vés.ta)] & & & $\mathrm{i}$ b u l a $! \mathrm{r}$ & \\
\hline
\end{tabular}


Ao contrário da Hipocorização, o Truncamento procura maximizar a identidade entre forma plena e forma encurtada. Por esse motivo, MAX-BT ocupa posição mais destacada que MAX-BH, sendo ranqueda acima de um restritor de palavra prosódica (ANALISE- $\sigma$ ). Em decorrência, truncamentos tendem a preservar o conteúdo segmental que poderia levar à raiz da forma de base. Esse material pode, de fato, associar-se a uma verdadeira raiz ('delegado' $>$ 'delega') ou não ('sapatão' > 'sapa'), o que sugere ser o Truncamento um processo de analogia: o falante parece interpretar a construção plena como constituída de radical + sufixo e, retirando o suposto afixo, acrescenta a vogal -a, marca de Truncamento, formando, assim, uma nova palavra, igualmente complexa do ponto-devista morfológico.

A Teoria da Correspondência, ao estender a esfera de atuação dos restritores de fidelidade, possibilita descrever operações não-concatenativas de modo bastante natural, permitindo explicitar e explicar diferenças entre processos bastante semelhantes, como a Hipocorização e o Truncamento. A Simpatia (McCarthy, 1998), surgida no final da década de 90, oferece instrumentos igualmente eficazes para analisar não só a opacidade fonológica, como também processos morfológicos que parecem fazer referência a um nível intermediário de representação, como é o caso da formação de hipocorísticos em português. Na seção seguinte, apresento uma análise, mais "simpática" e econômica, para a presença de consoantes idênticas nos hipocorísticos. Antes disso, porém, cumpre situar a Simpatia historicamente, mostrando o problema que levou a otimalidade paralelista a redefinir, mais uma vez, o papel das restrições de fidelidade.

\section{Restrições de Fidelidade \& Simpatia}

A opacidade fonológica constitui sério problema para abordagens nãoserialistas da OT, uma vez que parece requerer níveis intermediários de representação. Uma regra é considerada opaca se o ambiente que a engatilha, no input, não está presente no output. Dito de outra maneira, uma operação é aplicada no curso da derivação, mas seu ambiente não é visível na forma final. Nos termos de Kiparsky (1973: 79), uma regra do tipo $A \rightarrow$ $B$ / C-D é opaca se há estruturas de superfície com $B$ que ocorrem em outros ambientes que não $C-D$. Um típico caso de opacidade é ilustrado nas seguintes formas do hebreu tibetano, analisadas por McCarthy (1998): 
(39) (a) epêntese de /e/ em grupos consoânticos finais $\varnothing \rightarrow[\mathrm{e}] / \mathrm{C}-\mathrm{C} \quad(\mathrm{ex} .:$ /melk/ $\rightarrow$ [melek] 'rei')

(b) apagamento da oclusiva glotal em coda

$/$ ? $\rightarrow \varnothing /-$ ] $\sigma \quad$ (ex.: /qara?/ $\rightarrow$ [qara] 'ele chamou')

Essas regras podem interagir, caso a forma subjacente apresente uma oclusiva glotal como segundo elemento de grupo consonântico final, como se vê em (40). Nesse caso, a epêntese é engatilhada por um processo que conspira contra grupos consonânticos tautossilábicos (40a) e a queda de /?/ , por uma operação que bane oclusivas glotais em coda (40b). As regras (40a) e (40b) são ordenadas intrinsecamente (Kiparsky, 1973), pois a deleção de /?/, se aplicada primeiramente, destruiria o ambiente da epêntese. Com efeito, a representação de superfície (/dese/) não apresenta o segmento que engatilhou a inserção vocálica, uma vez que ele foi apagado no curso da derivação.

(40) Representação subjacente: /des?/

Regra 1: Epêntese de [e] dese?

Regra 2: Deleção de /?/ dese

Representação de superfície: [dese]

Modelos paralelistas - cujos níveis de representação relevantes são basicamente o input e o output - não conseguem tratar a opacidade de modo consistente. No caso em questão, não há justificativa relevante para a presença da vogal média na forma de superfície. A opacidade é problemática porque nenhum ranqueamento possível levaria à escolha do output correto. Vejamos como fica a análise de (40) através de uma hierarquia de restrições.

Uma vez que a epêntese ocorre para desfazer um grupo consonântico, *COMPLEX, uma restrição que proíbe margens complexas, domina DEP$\mathrm{IO}$, que bane inserções no output. Além disso, sílabas com oclusivas glotais em coda também não são permitidas e, portanto, CODA COND, que limita a presença sílabas travadas, deve ser ranqueada acima de MAX-IO, que determina a realização de todos os segmentos do input. Uma possível hierarquização é formalizada em (41): 
Como demonstrado em (42), o ranqueamento leva à escolha de um candidato transparente ([des]), que, entretanto, não é verdadeiro output. Por violar apenas MAX-IO, a forma selecionada é melhor que [dese] (o vencedor desejável, assinalado por : $)$ ), que infringe MAX-IO e DEP-IO. Dois concorrentes, (a) e (c), são sumariamente eliminados pelas condições de marcação ${ }^{12}$, mais bem cotadas na hierarquia que as de fidelidade. Apesar de dominadas, as restrições de fidelidade são decisivas na escolha do vencedor. Por não apresentarem a oclusiva glotal, (b) e (d) igualmente violam MAX-IO, mas o primeiro não insere material fônico, atendendo à exigência imposta por DEP-IO. Nenhum reordenamento resolveria o problema, pois [des] é, sem dúvida, mais fiel à base que [dese ${ }^{13}$.

\begin{tabular}{|c|c|c|c|c|c|}
\hline \multicolumn{2}{|c|}{ /des?/ } & $\begin{array}{l}\text { CODA } \\
\text { COND }\end{array}$ & *COMPLEX & $\begin{array}{l}\text { MAX- } \\
\text { IO }\end{array}$ & $\begin{array}{c}\text { DEP } \\
-I O\end{array}$ \\
\hline a. & [des?] & $* !$ & * & & \\
\hline b. & [des] & & & $*$ & \\
\hline c. & [dese?] & $* !$ & & & $*$ \\
\hline d. : & [dese] & & & $*$ & $* !$ \\
\hline
\end{tabular}

O problema da menor identidade para com o input decorre da falta de referência a um estágio intermediário de representação, mas tal procedimento contraria o paralelismo - um dos princípios básicos da OT (Prince \& Smolensky, 1993). Se houvesse como fazer referência a essa forma, seria possível manter o paralelismo e estabelecer um ranking que levasse à escolha do candidato opaco.

A Simpatia tenta remediar o problema da opacidade fonológica, dando status formal ao candidato que se aproxima da representação intermediária, na derivação serial, sem recorrer, entretanto, ao serialismo. Na proposta de McCarthy (1998), esse candidato é chamado de forma simpática e é escolhido (a) por obedecer a uma restrição seletora e (b) por melhor satisfazer as demais restrições da hierarquia.

\footnotetext{
12 Violações de outras restrições de marcação potencialmente significativas (p. ex., NÃO CODA) são irrelevantes, uma vez que seus efeitos não aparecem em outras formas de output, o que pressupõe ranqueamento abaixo das restrições de fidelidade.

13 Por exemplo, a inversão entre MAX e DEP levaria ao mesmo resultado e, nesse caso, MAX seria inoperante, uma vez que o destino de (d) já seria imediatamente selado por DEP.
} 
O modelo opera da seguinte maneira: o primeiro passo é determinar a restrição seletora de simpáticos e observar o comportamento dos candidatos em relação a ela. Se mais de um obedecer à exigência imposta pela restrição seletora, a forma simpática será a mais harmônica em relação à hierarquia estabelecida. Voltemos ao exemplo do hebreu tibetano. No caso em exame, a restrição seletora é MAX-IO, assinalada por (*). Dois candidatos satisfazem a condição de que "para cada segmento no input, há um segmento correspondente no output" e, portanto, há duas formas simpáticas possíveis: (a) e (c). Como (a) viola as duas restrições de marcação, (c) mais harmônico por não infringir *COMPLEX - é eleito forma simpática. No Tableau abaixo, esse candidato é representado por $(\alpha)$ e as violações fatais de Simpatia, por (i).

(43)

\begin{tabular}{|c|c|c|c|c|c|}
\hline \multicolumn{2}{|c|}{ /des?/ } & $\begin{array}{l}\text { CODA } \\
\text { COND }\end{array}$ & *COMPLEX & $\begin{array}{c}\text { * MAX- } \\
\text { IO }\end{array}$ & $\begin{array}{l}\text { DEP- } \\
\text { IO }\end{array}$ \\
\hline a. & [des?] & * & $i *$ & & \\
\hline b. & [des] & & & $i *$ & \\
\hline c. $\alpha$ & [dese?] & $*$ & & & $*$ \\
\hline d. & [dese] & & & $i *$ & $*$ \\
\hline
\end{tabular}

Uma vez escolhido o candidato simpático, a próxima tarefa é emparelhar o input com o output correto. Nesse caso, a restrição seletora passa a focalizar não mais a correspondência entre o input e os candidatos a output, mas a relação entre a forma simpática e os demais concorrentes. MAX-IO, a restrição seletora, mantém-se na hierarquia e dá origem à MAX- $\alpha \mathrm{O}$, que, nas palavras de McCarthy (1998: 17), determina que cada segmento do candidato simpático tenha um correspondente no output. Observem-se os efeitos de MAX- $\alpha \mathrm{O}$ no Tableau a seguir:

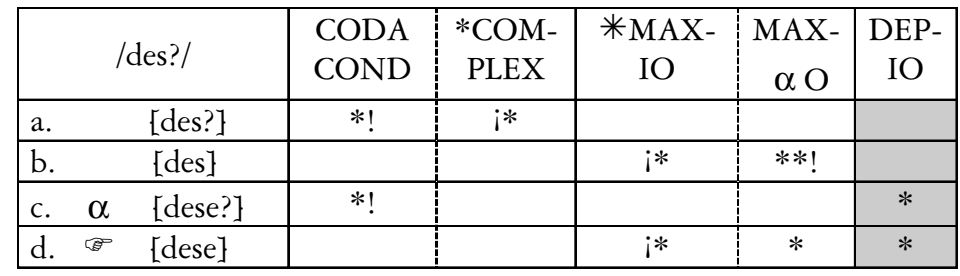


Em (44), os candidatos (a) e (c) são fatalmente eliminados pelas restrições de marcação. A terceira restrição, a seletora (*MAX-IO), tem duas funções: (1) avaliar todos os candidatos e (2) eleger a forma simpática. Como dois candidatos satisfazem MAX-IO, *COMPLEX é decisiva para determinar qual será o candidato simpático. Por ser mais harmônico que (a), (c) é escolhido como modelo para a avaliação de MAX- $\alpha$ O. Só há dois candidatos no páreo: (b) e (d). Nenhum deles satisfaz essa restrição, mas a violação de (b) é mais grave, uma vez que dois segmentos da forma simpática não aparecem nesse candidato. Por ser mais fiel em Simpatia, (d) é escolhido como output. ${ }^{14}$

Para assegurar a recuperabilidade da representação subjacente, a restrição seletora deve ser de fidelidade, isto é, tem de ser necessariamente uma restrição de correspondência Input-Output, como MAX, DEP e IDENT (McCarthy, 1998). Com a Simpatia, o componente AVAL passa a checar a identidade entre concorrentes a output, podendo as restrições de correspondência inter-candidatos levar à seleção de formas finais. Uma vez que a restrição seletora pertence à família 'correspondência I-O', o candidato simpático é mais fiel ao input que o próprio output.

Utilizando a Simpatia, é possível estabelecer uma diferença entre processos opacos e processos transparentes. Como o output é a forma que melhor satisfaz a hierarquia de restrições, é natural que ele também possa ser o candidato simpático (McCarthy, 1998). Quando isso acontece, o processo não é opaco porque há coincidência entre representação de superfície e forma simpática. Do contrário, a operação será opaca.

$\mathrm{Na}$ Simpatia, efeitos de opacidade na seleção de candidatos vencedores não são causados por serialismos residuais no design da Gramática, tal como sugere Kiparsky $(1997)^{15}$, já que tanto a escolha da forma simpática quanto a do output é feita em paralelo. A seleção do candidato- $\alpha$ deve

\footnotetext{
14 O tableau (43) deve ser interpretado apenas como didático, uma vez que a avaliação é feita num único momento, em (44), preservando-se, portanto, o princípio do paralelismo. Tanto a escolha do candidato simpático quanto a do output são feitas a partir de um único ranqueamento.

15 Kiparsky (1997) apresenta argumentos contrários a um enfoque radicalmente paralelista da OT. Além da opacidade, o autor mostra que abordagens paralelistas falham ao tentar explicar o desencadeamento e o bloqueio de determinados processos fonológicos provocados pela entrada de um afixo. Aproveitando as idéias básicas da Fonologia Lexical, Kiparsky propõe um modelo otimalista que incorpora a noção de estrato lexical - a chamada LPM-OT (Lexical Phonology-Morphology OT).
} 
preceder à do candidato- ${ }^{-}$, uma vez que o último depende do primeiro. $\mathrm{O}$ fato de A depender das propriedades de B não necessariamente implica, nas palavras de McCarthy (1998, p. 15), que há uma derivação serial, na qual B é construído antes de $A$. A é apenas modelo no qual B se espelha.

A seguir, proponho um exercício de aplicação da Simpatia à análise da Hipocorização, processo descrito, na seção anterior, à luz da Teoria da Correspondência. Naquela ocasião, frisei que discrepâncias entre antropônimos e hipocorísticos resultam não só do papel desempenhado pelos restritores de palavra prosódica (TODO-PÉ(D) e ANALISE- $\sigma$ ), como também da atuação de determinados restritores de ataque ([ONSET ${ }_{\sigma 1}=$ ONSET $\left._{\sigma 2}\right]_{\text {PWd }}$ e *[r ${ }_{\text {PWd }}$ ). No par 'Nazareno'/'Neno', por exemplo, só há três segmentos em comum porque as duas primeiras sílabas do antropônimo tiveram de ser apagadas para que o hipocorístico se ajustasse ao formato prosódico de uma palavra mínima. Uma nasal aparece como correspondente de um tepe pela impossibilidade de tepes figurarem, em português, na periferia esquerda de palavras prosódicas. Na representação a seguir, linhas sólidas indicam correspondência plena e linhas pontilhadas correspondência parcial.

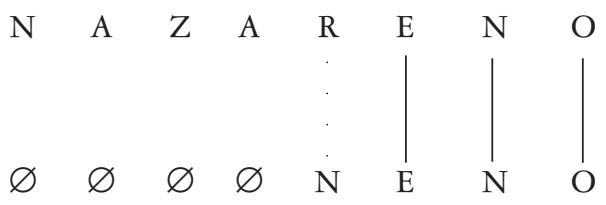

Em termos derivacionais, há, nos hipocorísticos, duas etapas de formação, como propõe Gonçalves (2004): (a) a delimitação de um molde, através da circunscrição prosódica positiva, que mapeia um troqueu moraico da direita para a esquerda do antropônimo e (b) a atuação de restritores de marcação sobre o molde, levando à emergência de estruturas não-marcadas no output final. Condições de minimalidade operam sobre o prenome, fazendo com que ele seja encurtado para se ajustar ao formato prosódico da Hipocorização. Dessa forma, as condições de marcação agem não no antropônimo, mas no molde propriamente dito. Portanto, diferenças entre o conteúdo escaneado pela circunscrição e o que efetivamente aparece nos hipocorísticos podem ser entendidas como resultantes do papel desempenhado pelas condições de boa-formação silábica sobre a porção da palavra-matriz que se projeta para o molde. Essas condições acabam 
sacrificando ainda mais a identidade prenome-hipocorístico, mas não incidem no input: agem no material copiado via circunscrição positiva, como no esquema a seguir:

(46) (antropônimo)

(Condições de Boa-

Formação Silábica)

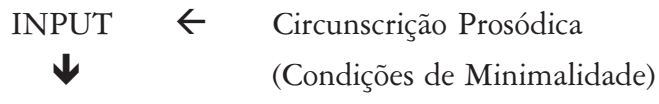

molde

OUTPUT (hipocorístico)

Como se vê em (46), há um nível de representação entre o input e o output, de modo que condições de minimalidade atuam no input (prenome), gerando um output (molde), que, por sua vez, passa a ser o input sobre o qual atuarão as condições de boa-formação silábica. Uma vez satisfeitas, essas condições levarão ao hipocorístico (output final). Nas palavras de Gonçalves (2004: 13), o "molde é a fôrma gerada pela circunscrição, mas também a forma a ser regulada pelas condições de boa-formação silábica".

A Hipocorização é, portanto, processo transderivacional, haja vista a necessidade, numa análise serialista, de um estágio intermediário de representação. Qual seria o status de '['re.no]' na formação do hipocorístico de 'Nazareno', se adotarmos um enfoque estritamente pararelista? Apesar de responsável pela substituição de /r/ por $/ \mathrm{n} /$, tal forma não constitui palavra independente no input, tampouco está plenamente manifestada no output. Dito de outra maneira, '['re.no]' não é forma de base e nem todos os seus constituintes fazem parte do output. Ainda assim, influencia na seleção do candidato vencedor de maneira decisiva, pois é ela que engatilha uma mudança de traços, por apresentar um segmento não-licenciado para a margem esquerda de PWd (45).

Defendo, neste artigo, a idéia de que o molde é uma instância específica da opacidade, nos termos de Kiparsky (1973), uma vez que vem a ser o pivô de uma série de modificações fonológicas. Tomando a formação de hipocorísticos como exemplo, pretendo mostrar que a Simpatia pode dar conta dos efeitos de opacidade envolvidos na Morfologia Não-Concatenativa, possibilitando abordar fenômenos tratados, na Morfologia Prosódica, através de procedimentos como a circunscrição e o molde. 
Na seção 2, argumentei que o hipocorístico é fiel ao input no que diz respeito à posição da cabeça de $\mathrm{PWd}$. Utilizando a restrição $\operatorname{DEP}(\mathrm{H})$ CABEÇA-PWd(FB), evidenciei que a identidade hipocorístico(H)-prenome(FB) é minimamente resguardada, uma vez que "cada elemento contido na cabeça prosódica de $H$ apresenta um correspondente em FB". Se DEP(H)-CABEÇA$\mathrm{PWd}(\mathrm{FB})$ funcionar como restrição seletora de simpáticos, é possível fazer referência ao molde e atribuir algum status formal a ele.

Adotando uma versão menos radical de DEP(H)-CABEÇA-PWd(FB), permiti correspondências parciais entre o hipocorístico e a forma de base. De fato, é possível interpretar o primeiro /n/ de 'Neno' como correspondente do /r/ de 'Nazareno' e, com isso, dar conta da substituição de /r/ por meio de restritores de onset, como foi feito em (32). No entanto, se adotarmos uma versão mais radical de correspondência, assumindo que cada elemento contido na cabeça prosódica de $H$ apresenta um correspondente idêntico em FB, a forma 'Neno', real hipocorístico de 'Nazareno', seria mal-sucedida frente a restrição de fidelidade I-O, por substituir um segmento de FB.

No Tableau abaixo, a hierarquização de *[r ${ }_{\text {Pwd }}$ abaixo de $\operatorname{DEP}(\mathrm{H})-$ CABEÇA-PWd(FB) faria de '['re.no]' o candidato vencedor. O verdadeiro output, identificado por (:), seria prontamente eliminado pela restrição de identidade I-O. De fato, nenhum candidato que se esforça em preservar a cabeça de palavra prosódica de FB pode ser mais fiel ao input que '['re.no]'. As formas (c) e (f) violam a penúltima restrição da hierarquia e não conseguem superar o rival transparente (a), que atende plenamente a condição expressa por DEP(H)-CABEÇA-PWd(FB).

\begin{tabular}{|c|c|c|c|c|c|}
\hline Input: /nazaréno/ & $\begin{array}{l}\text { PÉ- } \\
\text { BIM }\end{array}$ & $\begin{array}{l}\text { ANÁ- } \\
\text { LISE }\end{array}$ & $\begin{array}{l}\text { TODO- } \\
\text { PÉ(D) }\end{array}$ & $\begin{array}{c}\text { DEP- } \\
\text { PWd(FB) }\end{array}$ & $*[\mathrm{r}$ \\
\hline a. $\quad[($ ré.no $)]$ & & & & & $*$ \\
\hline [(ná.za) $]$ & & & & $\mathrm{n} ! \mathrm{a} \mathrm{z} \mathrm{a}$ & \\
\hline [(dé.no)] & & & & $\mathrm{d} !$ & \\
\hline$[($ né $)]$ & $* !$ & & & ro & \\
\hline [za (re.no)] & & $* !$ & & & \\
\hline f. $\quad: \quad[$ [né.no $)]$ & & & & $\mathrm{n} !$ & \\
\hline
\end{tabular}


Obviamente, um re-ranqueamento resolveria o problema, pois a dominância de *[r $\mathrm{r}_{\mathrm{PWd}}$ sobre $\mathrm{DEP}(\mathrm{H})$-CABEÇA-PWd $(\mathrm{FB})$ levaria à eliminação da forma mais fiel ao input. Nos casos em que o molde se inicia por vogal ('Mariana'), também temos de hierarquizar ONSET acima da restrição de fidelidade I-O, o que possibilita eliminar o candidato sem ataque ('Ana'). Teórica e metodologicamente possível, essa solução garante a seleção dos candidatos mais fiéis ao input quando o molde tem condições estruturais de funcionar como hipocorístico, seja por não apresentar /r/ na margem esquerda de PWd, seja por possuir o constituinte onset. De fato, a maioria absolta dos hipocorísticos do português é extremamente fiel à cabeça de palavra prosódica da Forma de Base (p. ex., 'Lena', de 'Marilena', e 'Mena', de 'Filomena') porque os moldes se ajustam bem às imposições ao preenchimento do ataque. No entanto, a dominância de ONSET e * [r ${ }_{\text {PWd }}$ sobre $\mathrm{DEP}(\mathrm{H})-\mathrm{CABEÇA-PWd}(\mathrm{FB})$ cria um problema: qual será o primeiro ataque do hipocorístico nos casos em que o molde não pode ser o output? Assumindo-se que *[r ${ }_{\text {PWd }}$ domina DEP(H)-CABEÇA-PWd(FB), dois candidatos de (47) ainda permaneceriam na disputa: (c) e (f), como se vê no Tableau abaixo. Uma restrição ranqueada mais baixo seria, portanto, decisiva, pois, em princípio, qualquer candidato que minimamente preserve os segmentos da cabeça de FB (p. ex., 'Leno' e 'Beno') é melhor que '['re.no]', sumariamente eliminado por $*\left[\mathrm{r}_{\mathrm{PWd}}\right.$.

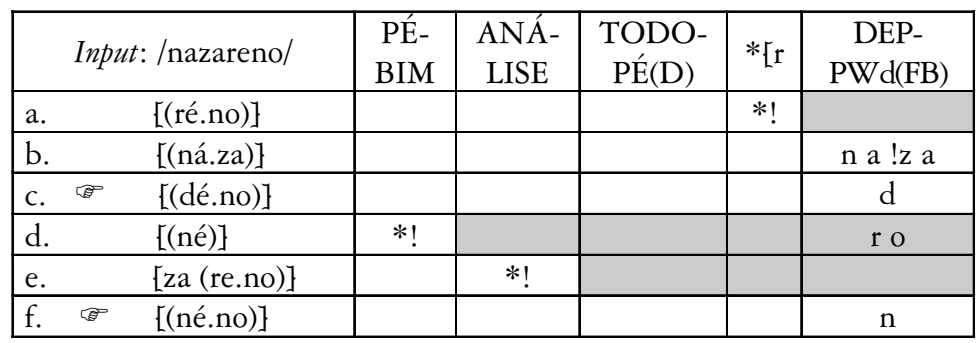

Como se vê em (48), 'Neno' e 'Deno' são os candidatos que melhor satisfazem a hierarquia, uma vez que violam minimamente o restritor de identidade I-O, substituindo apenas o segmento inicial da cabeça de PWd de FB. Como a forma (48b) não dispõe de correspondentes para os quatro elementos da cabeça de PWd de FB, não consegue superar os rivais (48c) e (48d), sendo, portanto, eliminada da competição. 
Na seção anterior, a restrição responsável pela escolha de 'Neno' foi $\left[\mathrm{ONSET}_{\sigma 1}=\mathrm{ONSET}_{\sigma 2}\right]_{\mathrm{PWd}}$, que requer ataques idênticos no nível da palavra prosódica. Uma vez que esse restritor não apresenta motivação que efetivamente justifique seu uso, considero a análise pela Simpatia mais elegante e mais econômica que pela Teoria da Correspondência, tornando desnecessária a utilização de restrições como essa. Na verdade, a igualdade de onsets resulta da impossibilidade de hipocorísticos se iniciarem por tepes ou por vogais. O preenchimento do primeiro ataque não é arbitrário, posto que condicionado pelo onset da sílaba seguinte. Dito de outra maneira, o output final não deixa de ser fiel ao molde, uma vez que descarta qualquer onset diferente daquele que se encontra no interior da forma rastreada pela circunscrição prosódica positiva, como se vê em (49):

$$
\begin{aligned}
& \text { (49) } \text { Murilo }>\text { Lilo (*Nilo, *Dilo, *Bilo) } \\
& \text { Florinda }>\text { Dinda } \quad(* \text { Linda, } * \text { Ninda, } * \text { Minda }) \\
& \text { Nazareno }>\text { Neno } \quad(* \text { Meno, } * \text { Peno, } * \text { Deno }) \\
& \text { Mariana }>\text { Nana (*Lana, *Vana, *Mana) } \\
& \text { Joelma }>\text { Melma (*Lelma, *Delma, *Nelma) }
\end{aligned}
$$

Se for atribuído algum status formal ao molde, é possível fazer com que outra restrição monitore a semelhança entre ele e os demais concorrentes, sem recorrer ao serialismo. Utilizando a Simpatia, o molde pode servir como parâmetro para a avaliação dos demais candidatos a output, funcionando como forma simpática. Destaquei mais acima que o primeiro passo é a escolha da restrição seletora, que deve pertencer à família 'identidade I-O'. Na formação de hipocorísticos, essa restrição é DEP(H)-CABEÇA$\mathrm{PWd}(\mathrm{FB})$, que impõe correspondência idêntica entre as cabeças prosódicas de $\mathrm{H}$ e FB. Em (48), apenas dois candidatos - (a) e (e) - obedecem à exigência imposta pela seletora de simpáticos, mas a forma (48a) é mais harmônica em relação à hierarquia estabelecida, por não violar ANALISE- $\sigma$, ranqueada mais alto que $*\left[\mathrm{r}_{\mathrm{PWd}}\right.$. No Tableau abaixo, a restrição seletora, $\mathrm{DEP}(\mathrm{H})-\mathrm{CABEÇA-PWd}(\mathrm{FB})$, é assinalada por (*). Quatro candidatos cometem uma violação fatal de simpatia (i), deixando apenas (a) e (e) na disputa. Como (e) viola uma restrição mais bem cotada na hierarquia, (a) é eleito forma simpática, recebendo a marca $(\alpha)$. 


\begin{tabular}{|c|c|c|c|c|c|}
\hline Input: /nazareno/ & $\begin{array}{l}\text { PÉ- } \\
\text { BIM }\end{array}$ & $\begin{array}{l}\text { ANÁ- } \\
\text { LISE }\end{array}$ & $\begin{array}{l}\text { TODO- } \\
\text { PÉ(D) }\end{array}$ & $*[\mathrm{r}$ & $\begin{array}{l}\text { * DEP- } \\
\text { PWd(FB) }\end{array}$ \\
\hline a. $\quad \alpha[$ [ré.no $)]$ & & & & $*$ & \\
\hline b. $\quad[$ (ná.za) $]$ & & & & & niaza \\
\hline [(dé.no)] & & & & & $\mathrm{di}$ \\
\hline$[($ né $)]$ & * & & & & rio \\
\hline [za (re.no) $]$ & & $* i$ & & & \\
\hline [(né.no) $]$ & & & & & $\mathrm{ni}$ \\
\hline
\end{tabular}

Como se vê em (50), (a), embora seja o candidato simpático, não pode ser o hipocorístico de 'Nazareno' por infringir *[ $\mathrm{r}_{\mathrm{PWd}}$, uma restrição que domina a seletora de simpáticos. Uma vez selecionada a forma simpática, a próxima tarefa é emparelhar o input com o output correto e, nesse caso, outra restrição passará a focalizar a correspondência entre a forma simpática e os demais concorrentes. Esse restritor é DEP- $\alpha$ O, definido em (51) a seguir:

(51) DEP- $\alpha \mathrm{O}$ (DEPendência de $\mathrm{O}$ em $\alpha$ ):

Segmentos do output devem apresentar correspondentes no candidato simpático. Não pode haver acréscimo do domínio $\alpha$ para o domínio O.

A restrição formulada em (51) proíbe inserção do candidato simpático para o output. Dessa maneira, consoantes que não estejam presentes no candidato simpático não podem aparecer no hipocorístico, de modo que a melhor satisfação a DEP- $\alpha$ O é obtida pela dupla associação de correspondência de um segmento consonantal já existente no candidato simpático (no caso em exame, a nasal). Como se vê em (52a), todos os elementos do output aparecem no candidato simpático, mesmo que com correspondentes múltiplos. Em (52b), a oclusiva não tem qualquer paralelo no candidato simpático. As linhas de (52) devem ser interpretadas como de correspondência (não de associação):
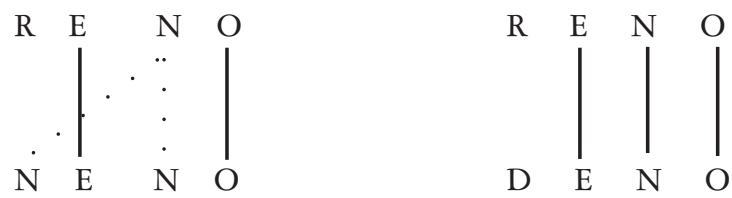
A correspondência de um-para-muitos, do domínio $\alpha$ para o domínio $\mathrm{O}$, é a solução encontrada para melhor resguardar a relação molde-output, tendo em vista que a inserção de uma consoante prejudica bem mais a identidade entre o antropônimo e o hipocorístico que dele se forma. Observem-se os efeitos de DEP- $\alpha \mathrm{O}$ no Tableau a seguir:

(53)

\begin{tabular}{|c|c|c|c|c|c|c|}
\hline Input: /nazareno/ & $\begin{array}{l}\text { PÉ- } \\
\text { BIM }\end{array}$ & $\begin{array}{l}\text { ANÁ- } \\
\text { LISE }\end{array}$ & $\begin{array}{c}\text { TODO- } \\
\text { PÉ }\end{array}$ & $*[\mathrm{r}$ & $\begin{array}{c}\text { * DEP- } \\
\text { PWd(FB) }\end{array}$ & $\begin{array}{c}\text { DEP- } \\
\alpha \mathrm{O}\end{array}$ \\
\hline a. $\alpha[($ ré.no $)]$ & & & & $* !$ & & \\
\hline b. $\quad[$ (ná.za) $]$ & & & & & in a $\mathrm{za}$ & $* * *$ \\
\hline c. $\quad[$ (dé.no) $]$ & & & & & $i d$ & $* !$ \\
\hline d. $\quad[($ né $)]$ & $* !$ & & & & iro & $* *$ \\
\hline e. $\quad[\mathrm{za}(\mathrm{re} . \mathrm{no})]$ & & $i * !$ & & & & \\
\hline f. $[$ (né.no) $]$ & & & & & $i n$ & \\
\hline $\begin{array}{ll}\text { g. } & \text { [(bé.no) }] \\
\end{array}$ & & & & & $i b$ & $* !$ \\
\hline
\end{tabular}

Em (53), os candidatos (d) e (e) são fatalmente eliminados pelos restritores de palavra prosódica. A forma (a) deixa a competição quando avaliada pela restrição de marcação $\left(*\left[r_{\text {PWd }}\right)\right.$. A quinta restrição, a seletora (*DEP(H)-CABE-ÇA-PWd(FB), não só monitora todos os candidatos, como também elege a forma simpática. Tendo em vista que dois concorrentes satisfazem a condição por ela imposta, ANALISE- $\sigma$ é decisiva na seleção do candidato simpático. Mais harmônico que (e), (a) é escolhido como modelo para a avaliação de DEP- $\alpha \mathrm{O}$. Nesse momento, só três candidatos seguem na disputa: (c), (g) e (f). Os dois primeiros não satisfazem essa restrição, por inserir um segmento sem qualquer paralelo no candidato simpático (as oclusivas $/ \mathrm{d} / \mathrm{e} / \mathrm{b} /$, respectivamente). Bem mais fiel em Simpatia, (f) é escolhido como output, uma vez que permite uma dupla correspondência para a nasal, que preenche as duas posições de ataque no hipocorístico, como foi visto em (52).

Sem recorrer ao serialismo, é possível fazer referência ao molde da Hipocorização e, com isso, evitar o uso de restrições que não têm qualquer motivação aparente, como $\left[\mathrm{ONSET}_{\sigma 1}=\mathrm{ONSET}_{\sigma 2}\right]_{\mathrm{PWd}}$, proposta na análise dos hipocorísticos com base na Teoria da Correspondência. Utilizando a Simpatia, pode-se, ainda, estabelecer uma diferença entre hipocorísticos opacos e transparentes. Nos casos em que o molde não se inicia por tepe ou 
por vogal, o output é a forma que melhor satisfaz a hierarquia de restrições, funcionando, também, como candidato simpático, como se vê no Tableau abaixo, para o input 'Marilena'. Nessa situação, são selecionados hipocorísticos mais transparentes. Quando o molde não apresenta ataque ('Mariana') ou tem um tepe na periferia esquerda de PWd ('Murilo'), o output não coincide com o candidato simpático, sendo o hipocorístico, portanto, mais opaco.

(54)

\begin{tabular}{|l|c|c|c|c|c|c|}
\hline Input: /marilena/ & $\begin{array}{c}\text { PÉ- } \\
\text { BIM }\end{array}$ & $\begin{array}{c}\text { ANÁ- } \\
\text { LISE }\end{array}$ & $\begin{array}{c}\text { TODO } \\
\text {-PÉ }\end{array}$ & $*[\mathrm{r}$ & $\begin{array}{c}* \text { DEP- } \\
\text { PWd(FB) }\end{array}$ & $\begin{array}{c}\text { DEP- } \\
\alpha \text { O }\end{array}$ \\
\hline a. $[$ (má.ri) $]$ & & & & & $i * ! * * *$ & $* * * * !$ \\
\hline b. $[$ (né.na) $]$ & & & & & $i * !$ & \\
\hline c. $[$ (lé.na) $] \alpha$ & & & & & & \\
\hline d. $[$ ri (lé.na) $]$ & & $i * !$ & & $*$ & & \\
\hline e. $[$ (mé.na) $]$ & & & & & $i * !$ & $*$ \\
\hline f. $[$ (ma)(lé.na) $]$ & $\mathrm{i} * !$ & & $*$ & & & \\
\hline
\end{tabular}

O Tableau (54) confirma a coincidência entre candidato simpático e output, havendo, no caso de 'Marilena', Hipocorização transparente. Por não obedecer à restrição seletora, os candidatos (a, b, e) cometem uma violação fatal de Simpatia. Dos remanescentes, (c) é o mais harmônico, sendo, pois, o candidato simpático. Da mesma forma, melhor satisfaz toda a hierarquia de restrições e é selecionado como output. Mais elegante e econômica, essa análise leva a generalizações bem mais consistentes, possibilitando expressar, com naturalidade e muita "simpatia", as relações de identidade envolvidas nos processos morfológicos não-concatenativos.

\section{Palavras Finais}

Operações morfológicas não-aglutinativas têm recebido considerável atenção na Morfofonologia Gerativa das duas últimas décadas. O principal foco de interesse vem sendo nos chamados "efeitos templáticos" de tais processos, que, na grande maioria das vezes, envolvem mapeamento de um constituinte morfológico para um molde prosódico menor, resultando, conseqüentemente, em perda de estrutura segmental. Enfoques sobre essas operações são variados, contribuindo substancialmente para o desen- 
volvimento da Morfologia Prosódica (McCarthy, 1986) e da Teoria da Correspondência (McCarthy \& Prince, 1995).

Neste artigo, procurei examinar o papel das restrições de fidelidade na emergência do Truncamento e da Hipocorização - processos de formação de palavras que promovem encurtamento de uma palavra-matriz para veicular carga emocional variada. Mostrando que a OT oferece instrumentos analíticos eficazes para descrever a modelagem morfoprosódica desses processos, evidenciei que a interação de restritores morfológicos, estruturais e de fidelidade possibilita (1) explicitar diferenças entre operações circunscritivas semelhantes e (2) levantar interessantes questões sobre o papel das relações de identidade em operações morfológicas sistematicamente condicionadas do ponto-de-vista fonológico.

Sem recorrer ao serialismo, é possível analisar a Hipocorização de modo bastante natural com os instrumentos da OT. No entanto, destaquei a necessidade de referência ao molde, estágio intermediário de representação numa abordagem derivacional, verdadeiro responsável por uma série de modificações fonológicas nos hipocorísticos. Utilizando a Simpatia (McCarthy, 1998), demonstrei que o molde (a forma simpática) pode ser utilizado como parâmetro de avaliação dos demais concorrentes a output, fazendo com que as restrições de fidelidade chequem as relações de correspondência entre candidatos.

Nos processos não-concatenativos, mudanças morfológicas aparecem para expressar a presença de um morfema numa representação menos superficial. Ao estender o alcance das restrições de fidelidade, a Teoria da Correspondência permite diferenciar operações não-aglutinativas de operações estritamente fonológicas: as primeiras podem atuar numa dimensão de correspondência $\mathrm{O}-\mathrm{O}$, enquanto as últimas se restringem à dimensão I-O. Apesar de diferentes nesse ponto, operações circunscritivas e fonológicas se assemelham em vários aspectos e talvez seja essa similaridade que tenha levado a OT a focalizar prioritariamente processos de interface Morfologia-Fonologia. De fato, são extremamente raros estudos sobre processos afixais realizados no âmbito da OT, cuja essência radicalmente paralelista vem sendo questionada por Kiparsky (1997).

Uma vez que a interação Morfologia-Fonologia não se restringe às operações circunscritivas, é necessário analisar os efeitos de MARCAÇÃO e FIDELIDADE também nos processos afixais. É nessa esfera que a OT 
vem sendo alvo de constantes críticas, pois processos fonológicos que requerem estratificação do léxico parecem se aplicar a outputs de níveis antecedentes (Kiparsky, 1997, p. 153). Por exemplo, o desencadeamento e o bloqueio de determinados processos provocados pela entrada de um afixo nem sempre são satisfatoriamente explicados por meio de uma única hierarquia de restrições: o output de um estrato lexical pode servir de input ao estrato seguinte.

Pouco se tem avançado na discussão sobre a autonomia da Morfologia em relação à Sintaxe e à Fonologia (Spencer \& Zwicky, 1998). Se constitui módulo independente da Gramática ou não, a Morfologia certamente vem contribuindo para o aprofundamento de questões teóricas e ocupando lugar de destaque na Lingüística contemporânea. Como fenômenos de interface estão na pauta de debates recentes no âmbito da OT, operações morfofonológicas sem dúvida alguma permitirão solucionar problemas empíricos e conceituais, possibilitando entender melhor a relação entre mudanças fonológicas motivadas morfologicamente e alterações puramente fonológicas, sejam elas explicadas em paralelo ou através de algum tipo de serialismo.

Recebido em dezembro de 2003

Aprovado em julho de 2004

\section{REFERÊNCIAS BibLIOGRÁFICAS}

Basílio, M. 1987. Teoria Lexical. São Paulo: Ática.

Benua, L. 1995. Identify effects in morphological truncation. In: BECKMAN, J. (ed.). Papers in Optimality Theory, 18 (1): 77-136.

Christófaro Silva, T. 1998. Fonética e Fonologia do português. São Paulo: Contexto.

Collischonn, G. 2000. A epêntese vocálica no português do Sul do Brasil: análise variacionista e tratamento pela Teoria da Otimalidade. Letras de Hoje, 35 (1): 285-318.

Costa, J. 2000. Gramática, conflitos e violações: uma introdução à Teoria da Optimalidade. Lisboa: Caminho.

De LaCy, P. 1999. Circumscriptive morphemes. In: Kitto, C. \& Swallwood, C. (eds.). Proceedings of the Sixty Meeting of the Austronesian Formal Linguistics Association. Holland: Hollan Academic Graphics. 
Dorigo, C. T. 2001. Fonologia Matsés: uma análise baseada em restrições. Tese de Doutorado em Lingüística. Rio de Janeiro: UFRJ/Faculdade de Letras, p. mimeo.

FuKazaWA, H. 1997. Multiple input-output faithfulness relations in japanese. Proceedings of MALC. Missouri: University of Missouri.

GNANADESIKAN, A. M. 1995. Markedness and faithfulness constraints in child phonology. Rutgers Optimality Archive, 67-0000, 48 p.

Gonçalves, C. A. 2003. Processos morfológicos não-concatenativos: tipologia e funcionalidade. ALFA - Revista de Lingüística, Araraquara, v. 42 , n. $1: 33-59$.

2004. Condições de minimalidade no molde da Hipocorização. Revista de Estudos da Linguagem, Belo Horizonte, v. 14, n. 1: 10-32.

Hale, M.; Kissock, M. \& ReIss, C. 2001. Output-output correspondence in Optimality Theory. Proceedings of WCCFL XVI. Missouri: University of Missouri.

Kager, R. 1999. Optimality Theory. Cambridge: Cambridge University Press. Kiparsky, P. 1973. Abstractness, Opacity and Global Rules. In: Fujimura, O. (ed.). Three Dimensions of Linguistic Theory. Tokyo: Tailusha, 1-136. Kiparsky, P. 1982. From cyclic phonology to lexical phonology. In: Der Hulst, V. \& SMITH, N. (eds.). The structure of phonological representation. Dordrecht: Foris Publications.

Kiparsky, P. 1997. Lexical Phonology \& Morphology. Iceland: Scancinavian Summer School in Generative Phonology.

LeE, S. H. 1999. Teoria da Otimalidade e silabação do PB. Trabalho apresentado no VI Congresso da ABRALIN. Florianópolis: UFSC, p. mimeo.

Massini-Cagliari, G. 1995. Cantigas de amigo: do ritmo poético ao lingüístico: um percurso bistórico da acentuação em português. Tese de Doutorado em Lingüística. Campinas: UNICAMP.

Mattoso Camara Jr., J. 1970. Estrutura da língua portuguesa. Petrópolis: Vozes. McCarthy, J. 1986. A prosodic theory of nonconcatenative morphology. Linguistic Inquiry, 12 (3): 373-417.

McCarthy, J. \& Prince, A. 1993. Generalized Alignment. In: Booij, G. E. \& MARLE, J. (eds.). Yerbook of Morphology. Dordrecht: Kluwer.

McCarthy, J. \& Prince, A. 1994. The emeergency of unmarked. Proceedings of NELS, 24 (1): 333-79.

McCarthy, J. \& Prince, A. 1995. Faithfulness and reduplicative identity. Rutgers: Rutgers University.

MCCARTHY, J. 1998. Sympathy E Phonological Opacity. Maryland: Workshop of Optimality Theory. 
Prince, A \& SMOlensky, A 1993. Optimality Theory: constraints and interaction in Generative Grammar. Boulder: University of Colorado/Rutgers University.

SANDERS, N. 2001. Intra-representacional Correspondence and Truncation. Master Dissertation in Linguistics. Rutgers: Rutgers University.

Sherrand, N. 1997. Optimality and Morphology. In: ArChangeli, D. \& Langendoen, D. (eds.). Optimality Theory: an overview. Malden and Oxford: Blackwell.

SiLVeIRA, C. M. da 2002. Cruzamento Vocabular em português: acaso ou processo? Dissertação de Mestrado em Língua Portuguesa. Rio de Janeiro: UFRJ/ Faculdade de Letras.

Spencer, A. 1991. Morphological Theory. Cambridge: Basil Blackwell.

Spencer, A. \& Zwicky, A. 1998. The Handbook of Morphology. Cambridge: Basil Blackwell.

Urbanczky. 1996. Patterns of Reduplication in Lushootseed. Doctoral Dissertation. Amhest: University of Massachusetts.

W ALTHER, M. 2002. Correspondence Theory: more candidates than atoms in the universe. Marburg: Institut für Germanistische Sprachwissenschaft. 